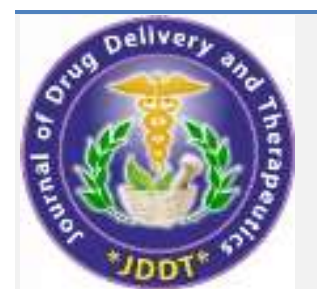

(을

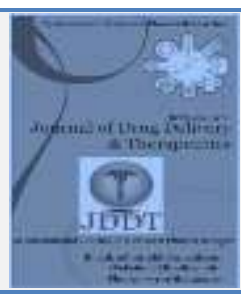

Research Article

\title{
Enhanced Antibacterial and Antioxidant Properties of Chitosan Films Blended with Gallic Acid and Incorporated with Thymol Silver Nanoparticles
}

\author{
Lade Bipin* (i), Kamdi Akash and Shanware Arti \\ Rajiv Gandhi Biotechnology Centre, Rashtrasant Tukadoji Maharaj Nagpur University (RTMNU), Nagpur 440033, Maharashtra, India
}

Article Info:

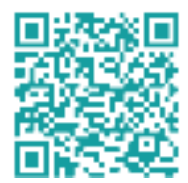

Article History:

Received 11 October 2021

Reviewed 30 November 2021

Accepted 07 December 2021

Published 15 December 2021

\section{Cite this article as:}

Lade B, Kamdi A, Shanware A, Enhanced Antibacterial and Antioxidant Properties of Chitosan Films Blended with Gallic Acid and Incorporated with Thymol Silver Nanoparticles, Journal of Drug Delivery and Therapeutics. 2021; 11(6-S):53-69

DOI: http://dx.doi.org/10.22270/jddt.v11i6-S.5130

*Address for Correspondence:

Lade Bipin, Rajiv Gandhi Biotechnology Centre, Rashtrasant Tukadoji Maharaj Nagpur University (RTMNU), Nagpur 440033, Maharashtra, India

ORCID ID: https://orcid.org/0000-0002-4132-1041

\author{
Abstract
}

In the present study, an attempt has been made to build and evaluate Chitosan+Glycerol/Gallic acid/Thymol-silver nanoparticles or chitosan blended (C+G/GA/TSNPs) film to significantly improve antioxidant and antibacterial activity for accelerated wound healing. Methanolic Gallic acid is used for the first time in antibacterial chitosan control $(\mathrm{C}+\mathrm{G})$ films. All developed films, compounds was Thymol and Gallic acid and their synthesized Thymol silver nanoparticles (T-SNPs) and Gallic acid silver nanoparticles (GASNPs) were characterized by Fourier-transform infrared spectroscopy (FT-IR), Scanning electron microscopy (SEM), X-Ray diffraction (XRD), Zeta potential (ZP), Dynamic light scattering (DLS), and UV-Vis spectroscopy. T-SNPs and GA-SNPs are rod and spherical in shape and were sufficient to reduce, capped, and stabilize. T-SNPs and GA-SNPs were measured Dynamic Light scattering and found to be $123.2 \mathrm{~nm}$ and $121.1 \mathrm{~nm}$ with surface charges of -19.7 and -20.3 respectively. The incorporation of methanolic Gallic acid and TSNPs into chitosan films, as predicted, effectively enhanced antioxidant and antimicrobial activity. The antimicrobial activity of Thymol, T-SNPs and C+G/GA/T-SNPs film showed more zone of inhibition than Gallic acid, GA-SNPs and $\mathrm{C}+\mathrm{G}$ film. The elasticity, texture and folding endurance of the $\mathrm{C}+\mathrm{G}$ film and $\mathrm{C}+\mathrm{G} / \mathrm{GA} / \mathrm{T}-\mathrm{SNPs}$ films have been substantially improved. The ecological quality of the generated $C+G$ and $C+G / G A / T-S N P s$ film was determined by the assessment of soil degradation and water degradation parameters. These findings lead to the conclusion that the $\mathrm{C}+\mathrm{G} / \mathrm{GA} / \mathrm{T}$-SNPs film produced with Gallic acid and T-SNPs can improve wound healing.

Keywords: Chitosan, Gallic Acid, Thymol Silver Nanoparticles, Antibacterial and Antioxidant Properties.

\section{INTRODUCTION}

Damage to the integrity of the skin leads to the formation of a wound that can occur anywhere in the body and adapts to spontaneous wound healing (Sahiner et al. 2017; Wang et al. 2020). The largest external organ in the human body, the skin, plays a crucial role in protecting the body from mechanical damage and microbial invasion. As a consequence, wound healing is the most important process for shielding the human body from serious injury.

In general, wound healing occurs in four phases; (1) haemostatic stage, (2) inflammatory response stage, (3) cell proliferation stage, and (4) collagen fibreremodeling stage. During the haemostatic transition, platelets, and fibrin coagulate successively to form thrombi, causing the skin wound to contract and preventing further blood loss. The inflammatory stage is characterized by the invasion of immune cells to provide optimal conditions for the eventual spread of fibroblasts. Consequently, cell proliferation occurs, where fibroblasts divide rapidly in response to various growth factors and secrete collagen fibers. These collagen fires grow and mature to complete the wound healing process. In the event that wounds lead to infection could lead to serious problems, thus care for wound healing is essential (Wang et al. 2020).

Chitosan, a deacetylated descendant of chitin, is widely used in the manufacture of biodegradable, biocompatible wound healing material. Chemically chitosan consists of $(1,4)$ linked 2-amino-deoxy-b-D-glucan. It has a wide range of applications in pharmacy, medicine, food, agriculture, textile products, hygiene, and water treatment due to improved mechanical, chemical, and biological properties. In addition, in order to improve the mechanical, hydrophobic, antimicrobial, and antioxidant properties of chitosan film, various active compounds have been complexed into chitosan film (Kaya et al. 2018).

Gallic acid is a phenolic compound chemically referred to as $3,4,5$ trihydroxybenzoic acid. It is a crystalline solid, slightly colorless, or slightly yellow with a molecular weight of $170.12 \mathrm{~g} / \mathrm{mol}$ and a molecular formula of $\mathrm{C}_{7} \mathrm{H}_{6} \mathrm{O}_{5}$. The melting point of Gallic acid is $210^{\circ} \mathrm{C}$ which decays between $235^{\circ}$ and $240^{\circ} \mathrm{C}$, which generates carbon dioxide and carbon monoxide (Fernandes et al. 2016). Gallic acid has been 
reported to stimulate various biological activities, such as antibacterial, anti-fungal, anti-viral, anti-inflammatory, antioxidant, anti-cancer, anti- diabetic, etc., which have potential in the food, medical, pharmaceutical, biotechnological, and cosmetic industries (Nayeen et al. 2016).

Thymol, chemically known as 2-isopropyl-5-methylphenol, is a white crystalline monoterpene phenol that gives thyme a strong flavor, a pleasant aromatic fragrance and strong antiseptic properties. Thymol is used as an antibacterial, antioxidant and also as a surgical disinfectant, a general disinfectant and anaesthetic agent (Marchese et al. 2016; Meeran et al. 2017). The pharmacophoric properties of Thymol are the phenolic hydroxyl group, in its chemical structure, which delivers defence-free radicals and increases the endogenous antioxidant.

Considering the different useful properties of the biopolymers Chitosan, Gallic acid, Thymol silver nanoparticles (T-SNPs), the purpose of this study was to produce wound healing chitosan blended $(\mathrm{C}+\mathrm{G} / \mathrm{GA} / \mathrm{T}-\mathrm{SNP})$ film, consisting of methanolic Gallic acid (antioxidant and wound healing), and incorporated T-SNPs (antibacterial). Synthesized $\mathrm{C}+\mathrm{G} / \mathrm{GA} / \mathrm{T}$-SNP film have been characterized physicochemically by solubility assay, UV spectrophotometer, Fourier Transform Infra-Red Spectroscopy (FTIR), Zeta Potential (ZP), X-Ray Diffraction (XRD), and Dynamic Light Scattering (DSL). In addition, essential properties such as biodegradability and water solubility are evaluated. Furthermore, the synthesized TSNPs, GA-SNPs, and Thymol and Gallic acid have been used for analysis of antimicrobial, antioxidant properties. In particular, $\mathrm{C}+\mathrm{G} / \mathrm{GA} / \mathrm{T}-\mathrm{SNPs}$ films have been tested for biological potential including antimicrobial, antioxidant, and wound healing activities.

\section{MATERIALS AND METHODS}

\subsection{Materials}

2.1.1. The solvents required for solubility test. The Acetic acid, Chloroform, Acetonitrile, Acetone, Formaldehyde, Toluene, Tert butyl alcohol, Ethyl ether, Methanol, 100\% alcohol, Tween 20, Dimethyl sulfoxide, N, N Dimethyl formamide, and doubled distilled water were of analytical grade (Sigma-Aldrich Chemicals).

2.1.2. The requirement for silver nanoparticles formulation. $250 \mathrm{~mL}$ flask, double distilled water, $100 \mathrm{~mL}$ measuring cylinder, Silver nitrate $\left(\mathrm{AgNO}_{3}\right)$ was purchased by Sigma-Aldrich.

2.1.3. The reagent used for Antioxidant activity. 2,2Diphenyl-1-Picrylhydrazyl (DPPH, Sigma-Aldrich Chemicals), Ascorbic acid (ACS Chemicals), and Methanol (Sigma-Aldrich Chemicals).

2.1.4. The reagent used for Antimicrobial analysis. Chitosan (medium molecular weight and $85 \%$ deacetylation degree, Cas No. 448877) was purchased from SIGMA-Aldrich, glycerol $\left(\mathrm{C}_{3} \mathrm{H}_{8} \mathrm{O}_{3}\right)$, Gallic Acid (Himedia), Thymol (S. D. Fine Chem. Limited), and Silver Nitrate $\left(\mathrm{AgNO}_{3}\right)$ (Sigma-Aldrich Chemicals).

2.1.5. The media and bacterial culture used in Antimicrobial assay. Nutrient Agar with composition as follows peptone (5.000 gms/Litre), sodium chloride (5.000 gms/Litre), HM peptone B\# (1.500 gms/Litre), Yeast extract $(1.500$ gms/Litre), Agar $(15.000$ gms/Litre) and final $\mathrm{pH}\left(\right.$ at $25^{\circ} \mathrm{C}$ ) $7.4 \pm 0.2$. The bacterial culture such as Escherichia coli, Klebsiella pneumoniae, Staphylococcus aureus, and Sporosarcina Pasteurii were gift from the Consultancy, Rajiv Gandhi Biotechnology
Centre, Rashtrasant Tukadoji Maharaj Nagpur University, L.I.T Premises, Nagpur, Maharashtra, India.

2.1.6 Materials for Chitosan films production. Chitosan and Gallic acid were purchased from Himedia and acetic acid $\left(\mathrm{CH}_{3} \mathrm{COOH}\right)$, glycerol $\left(\mathrm{C}_{3} \mathrm{H}_{8} \mathrm{O}_{3}\right)$, and methanol $\left(\mathrm{CH}_{3} \mathrm{OH}\right)$ were supplied from Sigma-Aldrich Chemicals.

\subsection{Solubility test of Thymol and Gallic acid}

The solubility of Thymol and Gallic acid was undertaken in various organic solvents. Analyzes were performed using 2 mg of Thymol and Gallic acid separately in the test tube and $5 \mathrm{~mL}$ of solvents were introduced and blended (Acetic acid, Chloroform, Acetonitrile, Acetone, Formaldehyde, Toluene, Tert-butyl alcohol, Ethyl ether, Methanol, 100\% alcohol, Tween 20, Dimethyl sulfoxide, and N, Dimethyl formamide) (Lade et al. 2014). Further, after a few minutes, the solubility and time needed for the solubility of Thymol and Gallic acid in various solvents were documented.

\subsection{Synthesis of silver nanoparticles of Thymol and Gallic acid using silver nitrate $\left(\mathrm{AgNO}_{3}\right)$}

Silver nanoparticles using Thymol and Gallic acid were synthesized by combining $95 \mathrm{~mL}$ of $1 \mathrm{mM}$ silver nitrate $\left(\mathrm{AgNO}_{3}\right)$ with $5 \mathrm{~mL}$ of $1 \%$ Thymol and Gallic acid separately. The reaction was performed in the presence of sunlight (March 2020; temperature $25-30^{\circ} \mathrm{C}$ ) and after 5 minutes, 1 $\mathrm{N}, \mathrm{NaOH}$ solution was added to the mixture solution to maintain alkaline 8.5-9 pH (Lade et al. 2018).

\subsection{Characterization of synthesized T-SNPs and GA-SNPs}

The bio reduction of silver nitrate using 1\% Thymol and Gallic acid was monitored at various times from $0 \mathrm{~min}$ to 24 $\mathrm{hr}$ and visual examination for change in colour of the solution was observed. The T-SNPs and GA-SNPs were centrifuged (Spectrofuge $7 \mathrm{M}$ ) at 13,000 rpm for $15 \mathrm{~min}$ to forms colloidal pellets at the bottom. The synthesized TSNPs and GA-SNPs were used for characterization purposes.

\subsection{UV- Visible spectroscopy (UV-VIS)}

The synthesis of T-SNPs and GA-SNPs was studied using Shimadzu 1800 UV-Vis spectrophotometer was used for recording the UV-vis spectra using a $10 \mathrm{~mm}$ path length quartz cuvette (Chandra et al. 2018). The instrument was set for base line correction and auto zero using methanol. Measuring the UV-Visible spectra at a resolution of 200-800 nm.

\subsection{Fourier transforms infrared spectroscopy (FTIR) analysis}

The FTIR analysis of the Thymol, Gallic acid, T-SNPs, and GASNPs were carried out to identify the primary functional groups of the compounds. The FTIR measurements were carried out using an Agilent Technology Cary 630 FTIR spectrophotometer by employing the $\mathrm{KBr}$ disc technique. The FTIR spectrum of the formulation was recorded at a resolution of $4 \mathrm{~cm}-1$ in the transmission mode (4000-440 $\mathrm{cm}-1$ ) (Chandra et al. 2018).

\subsection{Zeta potential (ZP) analysis}

The surface charge on T-SNPs and GA-SNPs determined using zetasizer (nano ZS, malvern instrument Ltd., UK) at 25 ${ }^{\circ} \mathrm{C}$. The zeta potential determines the colloidal stability of particles and surface charge over nanoparticles. The T-SNPs and GA-SNPs are subjected to Brownian motions due to thermal energy that produces Rayleigh scattering (Chandra 2018; lade et al. 2018). Liquid samples of the nanoparticles $(5 \mathrm{~mL})$ were diluted with double distilled water $(50 \mathrm{~mL})$ using $\mathrm{NaCl}$ as suspending electrolyte solution (2 x10-2 M 
$\mathrm{NaCl}$ ). Connect a $1 \mathrm{ml}$ pre-filled syringe with the sample to a cell port and point the cell down (ports down), then slowly inject the sample to the middle of the circuit at the bottom of the cell that it has formed and make sure no bubbles form in the cell. Return the cell in the vertical position (ports up) and continue to inject the sample from the syringe. Fill to the most extreme level of the cell (complete volume $0.8 \mathrm{~mL}$ or $0.75 \mathrm{~mL}$ relying upon the cell). Then, at that point, make sure that the electrodes are completely immersed in the liquid and there are no bubbles in the cell. Remove the syringe and cap the filled cells with its two caps (Caputo et al. 2015).

\subsection{Dynamic light scattering (DLS) analysis}

The size and size distribution of particles in the colloids TSNPs and GA-SNPs were measured using a Nano ZS zetasizer system (Malvern Instruments). Measurement parameters were as follows: a laser wavelength of $633 \mathrm{~nm}(\mathrm{He}-\mathrm{Ne})$, a scattering angle of $173^{\circ} \mathrm{C}$ (fixed-without changing possibility), a measurement temperature of $25^{\circ} \mathrm{C}$, a medium viscosity of $0.8872 \mathrm{mPa} \cdot \mathrm{s}$ and a medium refractive index of 1.330, and material refractive index of 0.200 (Tomaszewska et al. 2013). Prior to DLS estimation, the colloid was gone through a $0.2 \mu \mathrm{m}$ polyvinylidene fluoride (PVDF) layer. The sample was loaded into quartz cuvette and five estimations were performed, for which the mean outcome was recorded. DLS studies were done in two modes: general purpose mode (with normal resolution) and multiple narrow modes (with high resolution).

\subsection{X-ray diffraction (XRD) analysis}

The crystal structures of T-SNPs and GA-SNPs were measured by a Rigaku ${ }^{\circledR}$ X-ray diffractometer (RINT2000, Tokyo, Japan) at a voltage of $40 \mathrm{kV}$ and $15 \mathrm{~mA}$. The scattered radiation was detected in the angular range $2 \theta=5-80^{\circ}$ with a scanning speed of $5 \%$ min (Cui et al. 2018).

\subsection{Scanning electron microscopy (SEM) analysis}

The morphology of T-SNPs and GA-SNPs were used for scanning electron microscopic analysis using Jeol 6390LA/OXFORD XMX N with accelerated voltage of $20 \mathrm{KV}$ in DST-SAIF Cochin, India (Lade et al. 2018).

\subsection{Antioxidant activity}

2.11.1. DPPH (2, 2'-diphenyl-1-picrylhydrazyl) radical scavenging assay. UV-visible spectrometry was applied to evaluate the scavenging rate of 2,2-diphenyl-1picrylhydrazyl (DPPH) radicals of Thymol, T-SNPs, Gallic acid, GA-SNPs, $\mathrm{C}+\mathrm{G}$ film, and $\mathrm{C}+\mathrm{G} / \mathrm{GA} / \mathrm{T}-\mathrm{SNPs}$ film. Briefly, $10 \mathrm{mg}$ of each sample was dissolved in $10 \mathrm{~mL}$ of methanol to give a concentration of $1 \mathrm{mg} / \mathrm{mL}$. Then prepared sample concentrations of $5,10,15,25$ and $50 \mu \mathrm{g} / \mathrm{mL}$ and make up the volume of each sample in methanol then add $75 \mu \mathrm{l}$ of $(1 \mathrm{mM})$ DPPH. The mixtures were incubated for $30 \mathrm{~min}$ in dark room condition and then measured at $517 \mathrm{~nm}$ via a Shimadzu UV-1800 UV spectrophotometer and IC50 (Inhibitory concentration to scavenge 50\% free radicals) is also determined. Lower the absorbance of the reaction mixture indicates higher free radicals scavenging activity. IC50 value denotes the concentration of sample required to scavenge $50 \%$ of the DPPH free radicals (Bhalodia et al. 2011). The capability to scavenge the DPPH radicals was calculated using the following equation. The investigation was repeated three times and the antioxidant activities for each example were processed with the following formula:

DPPH Scavenged $(\%)=\frac{\text { A control }- \text { A sample }}{\text { A control }} \times 100$

Where,
A control $=$ Absorbance of DPPH Solution.

A sample $=$ Absorbance of DPPH along with a different concentration of samples.

IC50 was calculated from equation of line obtained by plotting a graph of concentration versus $\%$ inhibition

\subsection{Antimicrobial activity}

Antimicrobial activity of Gallic acid, Thymol, T-SNPs and GASNPs effectively against Escherichia coli, Klebsiella pneumoniae, Staphylococcus aureus, and Sporosarcina Pasteurii were evaluated using agar well diffusion method.

2.12.1. Agar well diffusion method. Agar well diffusion method is broadly used to assess antimicrobial activity. The agar plate surface inoculated by spreading a volume of the microbial inoculums over the entire nutrient agar plate surface. Then, a hole with a diameter of 4 to $6 \mathrm{~mm}$ is punched aseptically with a sterile cork borer or tip, and a volume $(30 \mu \mathrm{L})$ of the antimicrobial agent or Thymol and Gallic acid solution at desired concentration is introduced into the well. Then, Nutrient agar plates are incubated at $37^{\circ} \mathrm{C}$ for 24 hours (Balouiri et al. 2016).

\subsection{Chitosan films production}

The two different types of $\mathrm{C}+\mathrm{G}$ films were produced, one of which were incorporated with Gallic acid methanolic extract and T-SNPs while the one was used as a control without incorporating any extract. Briefly, $1 \mathrm{~g}$ of chitosan was added to $100 \mathrm{~mL}$ of $1 \%$ acetic acid to make chitosan solution. The mixture was stirred for $24 \mathrm{~h}$ via magnetic stirrer. Then $1 \mathrm{~g}$ of Gallic acid was added to $5 \mathrm{~mL}$ methanol and was vortex (REMI CM-101, Vortex mixer) for $5 \mathrm{~min}$. Then $1 \mathrm{~mL}$ of methanol mixture and $1 \mathrm{~mL}$ liquid T-SNPs was incorporated with $50 \mathrm{~mL}$ of chitosan solution and $200 \mu \mathrm{l}$ of glycerol as plasticizer (Kaya et al. 2018). All solutions were homogenized at $26000 \mathrm{rpm}$ for $5 \mathrm{~min}$ with a homogenizer (Heidolph, Silent Crusher M). Each solution was poured into a plastic Petri plate and the Petri plates were kept at $30^{\circ} \mathrm{C}$ for 48 h. Finally, the films were collected from Petri plate and stored for further analysis.

\subsection{Characterization of chitosan control and chitosan blended film}

2.14.1. Visual appearance. The Visual appearance $C+G$ film and $\mathrm{C}+\mathrm{G} / \mathrm{GA} / \mathrm{T}-\mathrm{SNPs}$ film were observed for colour and physical form or appearance (Naik et al. 2019).

2.14.2. Determination of thickness. The thickness of each film was measured using screw guage (thickness tester) at different position of the film and the average was calculated (Naik et al. 2019).

2.14.3. Folding endurance. The folding endurance is expressed as the number of folds in films (number of times the film is folded at the same place, either to break the strip/ film or to develop visible cracks). The $C+G$ film and $C+G / G A / T-S N P$ s film was folded in the centre, between the fingers and the thumb and then opened. This was termed as one folding. The cycle was repeated till the film showed rupture or breaks in centre of film or folded up to 100 times which is considered satisfactory to reveal good film properties (Naik et al. 2019). The total numbers of folding were named as folding endurance value. This test was carried out on all the $C+G$ film and $C+G / G A / T-S N P$ s film for three times and the mean of three readings were recorded.

2.14.4. Biodegradability of film. Biodegradability was tried by using two unique strategies i.e., water solubility and soil 
degradation (Kaya et al. 2018). Both of the techniques were repeated thrice. Solubility in water and soil was determined by using the following equation:

$$
\text { WL }(\%)=\text { weight loss/initial weight } \times 100
$$

2.14.4.1. Solubility in water. For testing the films solubility in water, the films sample was cut into small pieces $(2 \times 2 \mathrm{~cm})$ and the initial dry weights were measured for all the two samples. Next, $20 \mathrm{~mL}$ of water was added to the films and were kept at room temperature for $72 \mathrm{~h}$. After $72 \mathrm{~h}$ of immersion of the film samples; they were dried at $60^{\circ} \mathrm{C}$ and were weight again.

2.14.4.2. Soil degradability. Small pieces of the dry films $(2 \times 2 \mathrm{~cm})$ were scaled and then put into the enrichment soil. Around $10 \mathrm{~mL}$ of water was added to the samples day by day and following 15-30 days the final weights were measured (Kaya et al. 2018).

2.14.5. Surface $\mathbf{p H}$. The $C+G$ film and $C+G / G A / T-S N P s$ film were left to swell for 1 hour on the surface of the agar plate, prepared by dissolving $2 \% \mathrm{w} / \mathrm{v}$ agar in warmed double distilled water with constant stirring and poured into the petridish to solidify at room temperature. The $\mathrm{pH}$ paper was placed on the surface of the swollen film and the $\mathrm{pH}$ was determined (Naik et al. 2019). The mean of three readings was recorded.

2.14.6. Fourier transforms infrared (FTIR) analysis. The FTIR analysis of the pure chitosan, $C+G$ film and $\mathrm{C}+\mathrm{G} / \mathrm{GA} / \mathrm{T}-\mathrm{SNPs}$ film was carried out to identify the primary functional groups of the compounds. The FTIR measurements were carried out using an Agilent Technology Cary 630 FTIR spectrophotometer. The FTIR spectrum of the formulation was recorded at a resolution of $4 \mathrm{~cm}-1$ in the transmission mode (4000$440 \mathrm{~cm}-1$ ) (Chandra et al. 2018).

2.14.7. X-ray diffraction analysis. The crystal structures of $\mathrm{C}+\mathrm{G}$ film and $\mathrm{C}+\mathrm{G} / \mathrm{GA} / \mathrm{T}-\mathrm{SNP}$ s film were measured by a Rigaku ${ }^{\circledR}$ X-ray diffractometer (RINT2000, Tokyo, Japan) at a voltage of $40 \mathrm{kV}$ and $15 \mathrm{~mA}$. The scattered radiation was detected in the angular range $2 \theta=5-80^{\circ}$ with a scanning speed of $5^{0} / \mathrm{min}$ (Cui et al. 2018).

2.14.8. SEM analysis. The morphology of $C+G$ film and $\mathrm{C}+\mathrm{G} / \mathrm{GA} / \mathrm{T}-\mathrm{SNPs}$ film were used for scanning electron microscopic analysis using Jeol 6390LA/OXFORD XMX N with accelerated voltage of $20 \mathrm{KV}$ in DST-SAIF Cochin, India (Lade et al. 2018).

2.14.9. Antimicrobial activity. Antimicrobial activity of $\mathrm{C}+\mathrm{G}$ film and $\mathrm{C}+\mathrm{G} / \mathrm{GA} / \mathrm{T}-\mathrm{SNPs}$ film effectively against Escherichia coli, Klebsiella pneumoniae, Staphylococcus aureus, and Sporosarcina Pasteurii were evaluated using agar disc diffusion method.

2.14.9.1. Agar disc diffusion method. Agar disc diffusion method is widely used to evaluate the antimicrobial activity. The agar plate surface inoculated by spreading a volume of the microbial inoculums over the entire nutrient agar plate surface. After 30 mins the $C+G$ film and $\mathrm{C}+\mathrm{G} / \mathrm{GA} / \mathrm{T}-\mathrm{SNPs}$ film $(2 \times 2 \mathrm{~cm})$ were placed on the semi dried inoculated plates using sterile forceps and press slightly in the centre of the film using the forceps. Then, agar plates are incubated at $37^{\circ} \mathrm{C}$ for 24 hours. The antimicrobial agent diffuses in the agar medium and inhibits the growth of microbial strain tested (Naik et al. 2019).

\section{RESULTS AND DISCUSSION}

The Present study investigated the antimicrobial and antioxidant potential of Thymol, Gallic acid, T-SNPs, and GASNPs. To validate, the solubility test of Gallic acid and Thymol in different solvents at the room temperature and characterized through the instruments such as UV-Visible Spectroscopy, Fourier Transform Infra-Red Spectroscopy, Zeta potential, and Dynamic Light Scattering. Further, the antimicrobial activity of Thymol and Gallic acid in different concentration was studied against four different bacterial cultures (E. coli, Klebsiella, S. aureus, and S. Pasteurii). Finally a $\mathrm{C}+\mathrm{G}$ film and $\mathrm{C}+\mathrm{G} / \mathrm{GA} / \mathrm{T}-\mathrm{SNPs}$ film is formulated and antimicrobial and antioxidant potential was evaluated against gram positive and gram negative bacteria.

\subsection{Solubility analysis of Thymol and Gallic acid}

The solubility of Thymol and Gallic acid were recorded in different types of solvent and distilled water. The Thymol was completely soluble in Acetic acid, Chloroform, Acetonitrile, Acetone, Formaldehyde, Toluene, Tert-butyl alcohol, Ethyl ether, Methanol, 100\% alcohol, Tween20, Dimethyl sulfoxide, and N, N Dimethyl formamide. However, Thymol was slightly soluble in distilled water. Similarly, it was observed that the Gallic acid was completely soluble in Acetone, Formaldehyde, Methanol, $100 \%$ alcohol, Dimethyl sulfoxide, and $\mathrm{N}, \mathrm{N}$ Dimethyl formamide in a minute and Gallic acid totally insoluble in Tween 20, Ethyl ether, Chloroform, and Toluene. Gallic acid incompletely soluble in Acetic acid, Acetonitrile, Tert-Butyl alcohol, and Distilled water. Yet, it was observed that after 14 hours Gallic acid was soluble in Acetonitrile, Tert-Butyl alcohol, and Distilled water. In the study of Lade et al. (2014) they have also performed similar kind of solubility test however, in that case they have used plant extract but in this case Thymol and Gallic acid pure compound were used. The solubility of compound assists to determine its utility in various drug and polymers complexation for pharmaceutical industries applications.

\subsection{Synthesis and visual characterization of T-SNPs and GA-SNPs}

The silver nanoparticles have been synthesized successfully using Gallic acid and Thymol has been synthesized by mixing $95 \mathrm{~mL}$ of $1 \mathrm{mM}$ silver nitrate $\left(\mathrm{AgNO}_{3}\right)$ with the $5 \mathrm{~mL}$ of $1 \%$ Gallic acid and Thymol independently under sun light conditions. Similarly, Lade and Patil et al. (2017) have used sunlight conditions for silver nanoparticles synthesis. In contrast, Li et al. (2015) have prepared silver nanoparticles by Gallic acid. They have used $2 \mathrm{~mL}$ of $\mathrm{AgNO}_{3}(20 \mathrm{mM})$ which was reduced with $2 \mathrm{~mL}$ of Gallic acid $(10 \mathrm{mM})$ at room temperature. Also, there are no reports of silver nanoparticles synthesis using Thymol under sunlight conditions. The change in colour of solution from transparent to dark brown and black colour was observed and confirmed the formulation of T-SNPs and GA-SNPs. The synthesis of T-SNPs and GA-SNPs are confirmed preliminary by observing change in colour from colourless, became dark brown colour of Thymol and black colour of Gallic acid. Similar change in colour for silver nanoparticles synthesis was observed by Lade and Patil et al. (2017).

\subsection{UV-Visible spectroscopy analysis of T-SNPs and GA- SNPs}

The UV-Visible absorption spectrum of T-SNPs and GA-SNPs is showed in Fig. 1. It is seen from the Fig. 1, the 1\% Thymol and $1 \%$ Gallic acid are sufficient to act as reducing agents to form silver nanoparticles. The formation of T-SNPs with absorbance of $0.7 \mathrm{~A}$ and GA-SNPs with absorbance of $0.6 \mathrm{~A}$ 
using Thymol and Gallic acid showed the well defined absorbance band at $415 \mathrm{~nm}$ and $410 \mathrm{~nm}$. The work of Li et al. (2015) suggested that the green synthesis of Gallic acidcoated silver nanoparticles UV-vis absorption spectrum of GA-SNPs shows typical and narrow absorption peak at approximately $400 \mathrm{~nm}$. However, the Tonello et al. (2018) have reported the UV-visible absorption spectra of $0.25 \mathrm{mM}$ Thymol at $550 \mathrm{~nm}$ with absorbance of $0.7 \mathrm{~A}$.

\subsection{FT-IR analysis of Thymol, T-SNPs, Gallic acid and GA-} SNPs

3.4.1. FT-IR analysis Thymol and T-SNPs. In order to conclude the molecular interactions in the functional groups present in Thymol and silver $\mathrm{AgNO}_{3}$ to form T-SNPs, the FTIR analysis was carried out. The FTIR spectra of Thymol and T-SNPs are shown in Fig. 2.In the spectrum of Thymol, the Characteristic FTIR spectra were recorded with the functional groups as $\mathrm{C}-\mathrm{Cl}$ Stretch (Halo Compound) $1058.675 \mathrm{~cm}-1$, C-N Stretch (Amine) $1241.722 \mathrm{~cm}-1, \mathrm{C}-\mathrm{O}$ Stretch (Aromatic ester) $1285.521 \mathrm{~cm}-1$, O-H Stretch (Alcohol) $1419.674 \mathrm{~cm}-1, \mathrm{~N}-\mathrm{O}$ Stretch (Nitro compound) $1516.336 \mathrm{~cm}-1, \mathrm{~N}-\mathrm{H}$ Bending (Amine) $1584.503 \mathrm{~cm}-1, \mathrm{C}=\mathrm{C}$ Stretch $(\alpha, \beta$ unsaturated ketone group) $1619.383 \mathrm{~cm}-1, \mathrm{C}-\mathrm{H}$ Bending (aromatic compound) $1742.610 \mathrm{~cm}-1, \quad \mathrm{~N}=\mathrm{N}=\mathrm{N}$ Stretch (Azide compound) $2106.625 \mathrm{~cm}-1, \mathrm{O}-\mathrm{H}$ Stretch (Carboxylic acid) $2869.304 \mathrm{~cm}-1$.

As seen from the spectrum of T-SNPs, structural changes occurred during the silver nanoparticles synthesis. The intermolecular interactions were observed in C-N Stretch (1058.675 cm-1) and conjugation to strong C-F Stretch $(1016.018 \mathrm{~cm}-1)$. Also, the C-N Stretch $(1156.541 \mathrm{~cm}-1)$ is shifted to C-F Stretch (1113.295 cm-1). The shifting of O-H Stretch (1419.674 $\mathrm{cm}-1$ ) from the Thymol was recorded to O-H Bending (1404.368 cm-1) in synthesized silver nanoparticles. A complete transformation of band was observed in $\mathrm{C}=\mathrm{C}$ Stretch $\alpha, \beta$ Unsaturated ketone $(1619.383 \mathrm{~cm}-1)$ to $C=C$ Stretch Alkene (1638.056 cm-1). The peak absorption at $\mathrm{N}=\mathrm{N}=\mathrm{N}$ Stretch Azide $(2106.625 \mathrm{~cm}-1)$ was changed to $\mathrm{N}=\mathrm{C}=\mathrm{S}$ Stretch Isothiocyanate $(2010.053 \mathrm{~cm}-1)$. The peak shift in O-H Stretch $2603.778 \mathrm{~cm}-1$ and3173.427 $\mathrm{cm}-1$ to $\mathrm{C} \equiv \mathrm{C}$ Stretch $(2205.048 \mathrm{~cm}-1)$, and C-H Stretch (3324.369 cm-1) was observed for T-SNPs.

3.4.2. FT-IR analysis Gallic acid and GA-SNPs. FTIR spectroscopy was used in order to characterize Gallic acid and GA-SNPs. As can be seen in Fig. 2. C-Cl Stretch are observed around $732.969-789.011 \mathrm{~cm}-1$ are the Halo Compound of Gallic acid, C-N Stretch at $1017.853 \mathrm{~cm}-1-1235.695 \mathrm{~cm}-1$ are associated with Amine group, additionally the characteristics band of $\mathrm{O}$ -
$\mathrm{H}$ Bending are observed at $1305.573 \mathrm{~cm}-1$ are for Phenol group. The C-H Bending at $1438.510 \mathrm{~cm}-1$ to $1535.999 \mathrm{~cm}-1$ are specific for Alkane functional group in Gallic acid. Moreover, the $\mathrm{C}=\mathrm{C}$ Stretch was recorded at $1611.774 \mathrm{~cm}-1$ corresponds to $\alpha, \beta$ Unsaturated ketone.

Chandra et al. (2018) suggested the absorption peak recorded at 1685, 1579, 1571 and $1481 \mathrm{~cm}-1$ was assigned for vibration stretch of $\mathrm{C}-\mathrm{C}$ bonds in an aromatic group. Various peaks observed in $1313-1020$ cm-1 regions corresponded to $\mathrm{C}-\mathrm{O}$ stretch vibration bond and bending vibration of $\mathrm{O}-\mathrm{H}$ bond of phenol Gallic acid (GA).

The C-H Bending stretches from $1694.253 \mathrm{~cm}-1$ to $1993.963 \mathrm{~cm}-1$ are specific for Aromatic compound. $\mathrm{C} \equiv \mathrm{C}$ Stretch at wavelength $2117.161 \mathrm{~cm}-1$ is for Alkyne. The O-H Stretch observed at 2652.804 to $3063.549 \mathrm{~cm}$ 1 belongs to Carboxylic acid and 3268.788 to 3469.614 $\mathrm{cm}-1$ is specific for Alcohol.

As seen from the spectrum of GA-SNPs, C-N stretching vibration band is observed around $1017.853 \mathrm{~cm}-1$, indication of the Amine groups of Gallic acid and is shifted to C-F Stretch at $1016.107 \mathrm{~cm}-1$ specific for Alkyl halide in silver nanoparticles. Furthermore, $\mathrm{C}=\mathrm{C}$ Stretch stretching vibration band moved slightly to higher wave numbers, from $1611.774 \mathrm{~cm}-1$ for Gallic acid to $1637.501 \mathrm{~cm}-1$ for the silver nanoparticles. This kind of shift of such bands indicates physical interactions between Gallic acid and silver nitrate. Additionally, the C-H Bending (1914.176 cm-1) belongs to Aromatic compound which are modified into $\mathrm{C}=\mathrm{C}=\mathrm{C}$ Stretch (1918.218 cm-1) as allene, suggesting intermolecular interaction among themselves. Moreover, the $\mathrm{C} \equiv \mathrm{C}$ Stretch $(2117.161 \mathrm{~cm}-1)$ are modified to $\mathrm{N}=\mathrm{C}=\mathrm{S}$ Stretch $(2083.241 \mathrm{~cm}-1)$ as isothiocyanate. The peak shifted in $\mathrm{O}-\mathrm{H}$ Stretch $3268.788 \mathrm{~cm}-1$, and $3343.388 \mathrm{~cm}-1$ to $\mathrm{O}-\mathrm{H}$ Stretch $(3266.524 \mathrm{~cm}-1)$ and $(3310.658 \mathrm{~cm}-1)$ was observed for GA-SNPs.

The Park et al. (2016) indicates the appearance of broad band's at $3422 \mathrm{~cm}-1$ for GA-AgNPs confirmed the existence of intermolecular hydrogen bonds of phenolic groups on the surface of the nanoparticles and Chandra et al. (2018) shows a broadband peak between 3552 and $2500 \mathrm{~cm}-1$ and the narrow peak at $1772 \mathrm{~cm}-1$ due to the stretching vibration of $\mathrm{O}-\mathrm{H}$ (alcohol) group and a $\mathrm{C}-\mathrm{O}$, which confirms the presence of carboxyl group in the Gallic acid. This carboxyl group binds to the surface of the AgNPs. These bonds wholly disappeared after the nanoparticles synthesis.
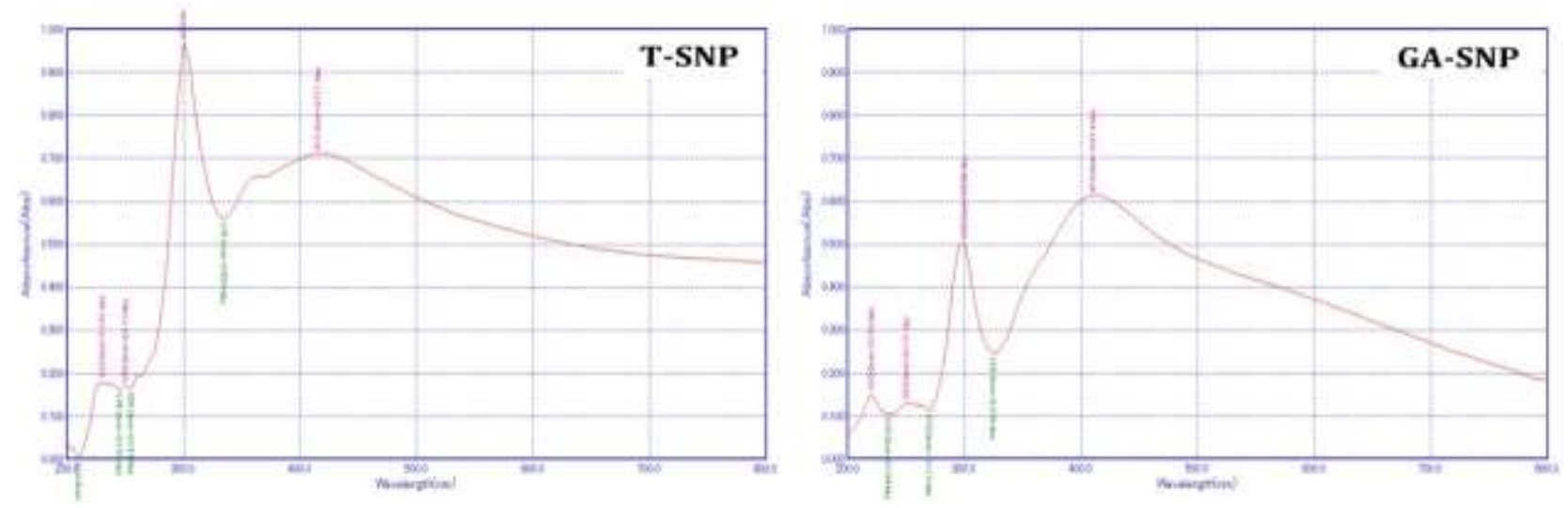

Figure 1: The UV-visible absorption spectra of Thymol silver nanoparticles (T-SNPs) and Gallic acid silver nanoparticles (GA-SNPs) 

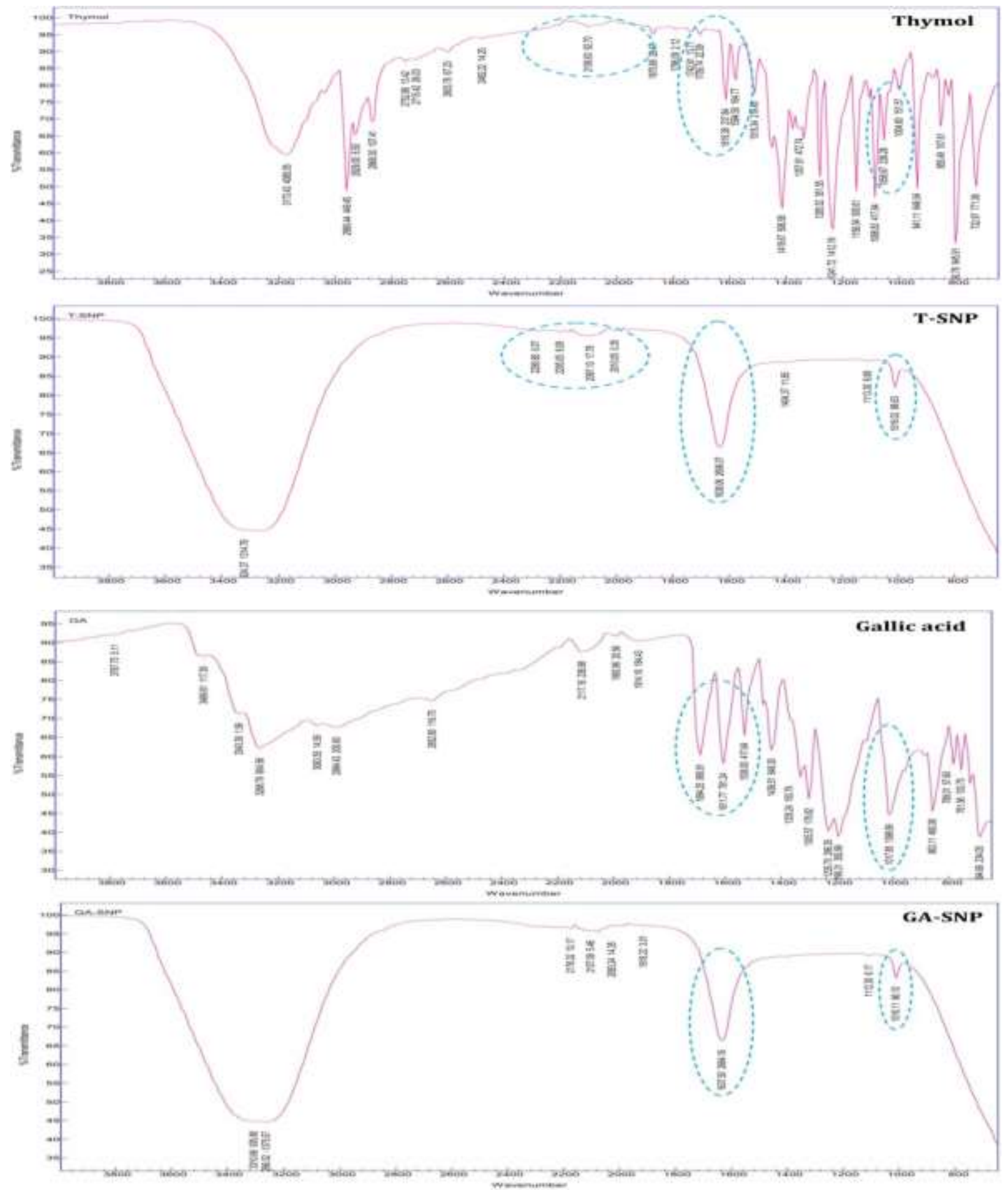

Figure 2: Display the FT-IR Spectra of Thymol and Gallic acid compound possessing several functional groups and the FT-IR Spectra of synthesized Thymol silver nanoparticles (T-SNPs) and Gallic acid silver nanoparticles (GA-SNPs)

\subsection{Zeta potential analysis of T-SNPs and GA-SNPs}

The surface charge, zeta deviation and conductivity on the synthesized T-SNPs and GA-SNPs were recorded using the Zeta Potential. The Zeta potential results are presented in Fig. 3. As is seen from the Fig. 3, average zeta potential, zeta deviation and conductivity value was found to be $-19.7 \mathrm{mV}$, $9.70 \mathrm{mV}$, and $0.105(\mathrm{mS} / \mathrm{cm})$ for T-SNPs. However, the average zeta potential, zeta deviation and conductivity value for GA-SNPs was found to be $-20.3 \mathrm{mV}, 5.66 \mathrm{mV}$ and 0.115 $(\mathrm{mS} / \mathrm{cm})$. Although, the negative values -19.7 and -20.3 detected as a more regular stability of T-SNPs and GA-SNPs respectively. In the study of Li et al. (2015) it is reported that the Gallic acid-coated silver nanoparticles had a negative zeta potential distribution of $-10.5 \mathrm{mV}$ and were spherical in shape. The hydrodynamic diameter of GA-AgNPs evaluated by DLS was $17.6 \pm 5.3 \mathrm{~nm}$.

\subsection{Dynamic light scattering analysis of T-SNPs and GA-} SNPs

The size and size distribution of particles of colloids T-SNPs and GA-SNPs were measured by Dynamic Light scattering (see Fig. 3) and found to be $123.2 \mathrm{~nm}$ and $121.1 \mathrm{~nm}$ respectively. Li et al. (2015) reported the hydrodynamic diameter of GA-AgNPs evaluated by Dynamic Light scattering analysis was $17.6 \pm 5.3 \mathrm{~nm}$ and Abed et al. (2019) reported diameter of Thymol AgNPs $152 \mathrm{~nm}$. 


\subsection{X-ray diffraction of T-SNPs and GA-SNPs}

The exact nature of the silver particles can be presumed from XRD patterns of the T-SNPs synthesized using Thymol. The XRD pattern of the T-SNPs (see Fig. 4) showed four intense peaks in the whole spectrum of $2 \theta$ values ranging from 20 to 80 . The $2 \theta$ peaks observed at $38.08^{\circ}, 44.231^{\circ}$, $64.442^{\circ}$, and $77.375^{\circ}$ corresponds to (1 111 ), ( $\left.\begin{array}{lll}2 & 0 & 0\end{array}\right),\left(\begin{array}{lll}2 & 2 & 0\end{array}\right)$, and $\left(\begin{array}{lll}3 & 1 & 1\end{array}\right)$ reflection planes of an fcc lattice of silver (ICSD No. 98-018-0878), respectively (Kumar et al. 2017a, b) suggesting $\mathrm{AgNO}_{3}$ complete reduction by Thymol. The $38.08^{\circ}$ peak is showing high intensity due to preferred crystal orientation and the remaining peaks shows low intensity due to crystal arrangements in random manner. Generally, the broadening of peaks in the XRD patterns of samples signifies smaller particle size. From the XRD patterns, it indicates that the T-SNPs powders have large crystalline domain sizes in the mentioned concentration and correspond to pure Ag metal with face-centered cubic (fcc) symmetry. The other unassigned peaks could be due to the crystallization (bcc) of bioorganic phase that occurs on the surface of the nanoparticles.

Similarly, the XRD pattern of the GA-SNPs (see Fig. 4) showed four $2 \theta$ peaks at $38.08^{\circ}, 44.23^{\circ}, 64.44^{\circ}$, and $77.37^{\circ}$ that corresponds to (1 111$),\left(\begin{array}{lll}2 & 0 & 0\end{array}\right),\left(\begin{array}{lll}2 & 2 & 0\end{array}\right)$, and ( $\left.\begin{array}{lll}3 & 1 & 1\end{array}\right)$ reflection planes of a fcc lattice of silver (ICSD No. 98-0180878), respectively (Kumar et al. 2017a, b) suggesting $\mathrm{AgNO}_{3}$ complete reduction by Gallic acid. Therefore, an XRD pattern concludes that the GA-SNPs powders have large crystalline domain sizes and correspond to pure Ag metal with fcc symmetry. The Crystallite size Dp of GA-SNPs and T-SNPs are shown in Table 1 and Table 2 using Scherer's formula for Crystallite size $\mathrm{Dp}=\mathrm{K} \lambda /(\mathrm{B} \cos \theta)$. The average crystallite size from a sharp peak is estimated by using the Scherer's formula. The average crystallite size for GA-SNPs was found to be $25.20 \mathrm{~nm}$ and T-SNPs were found to be $28.31 \mathrm{~nm}$.

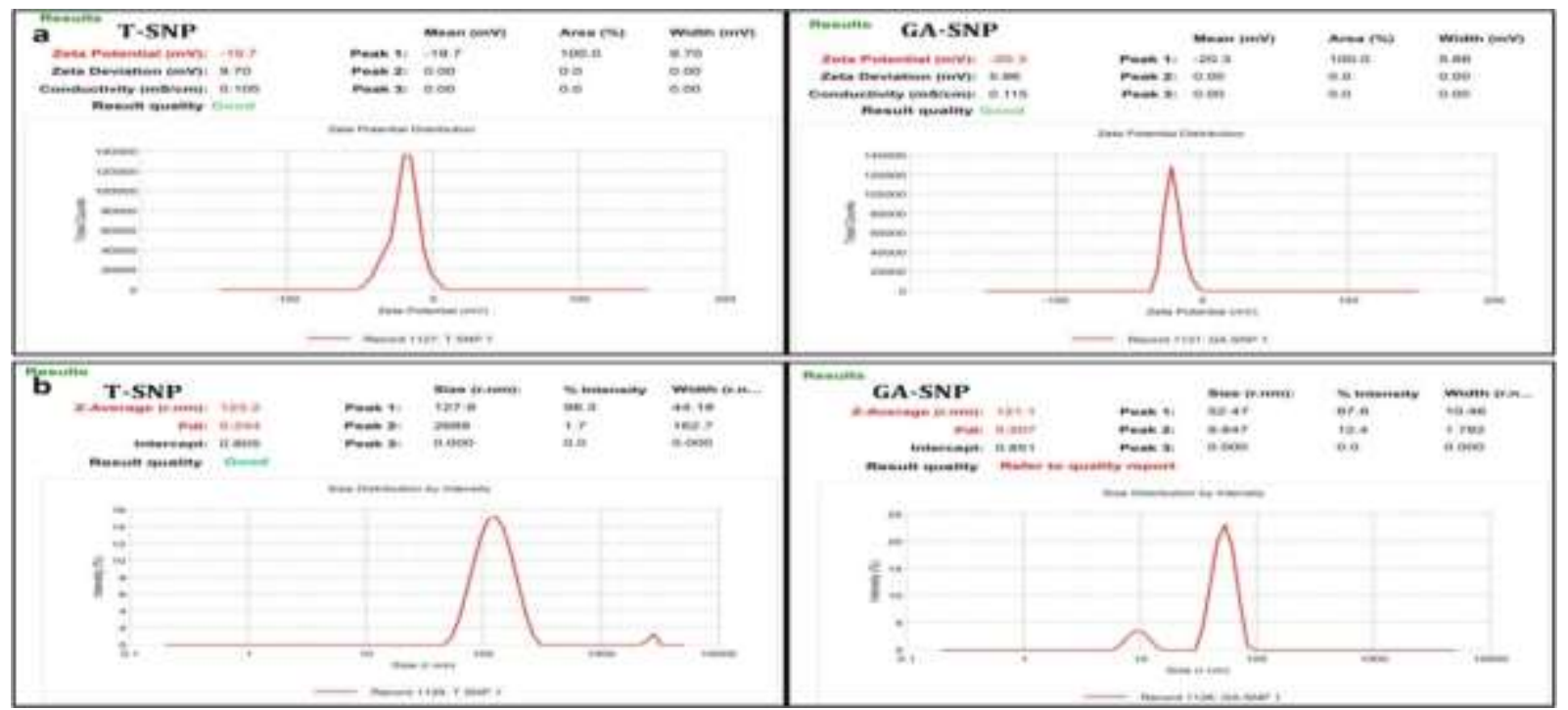

Figure 3: (a) Zeta potential and (b) Dynamic light scattering of Thymol silver nanoparticles (T-SNPs) and Gallic acid silver nanoparticles (GA-SNPs)
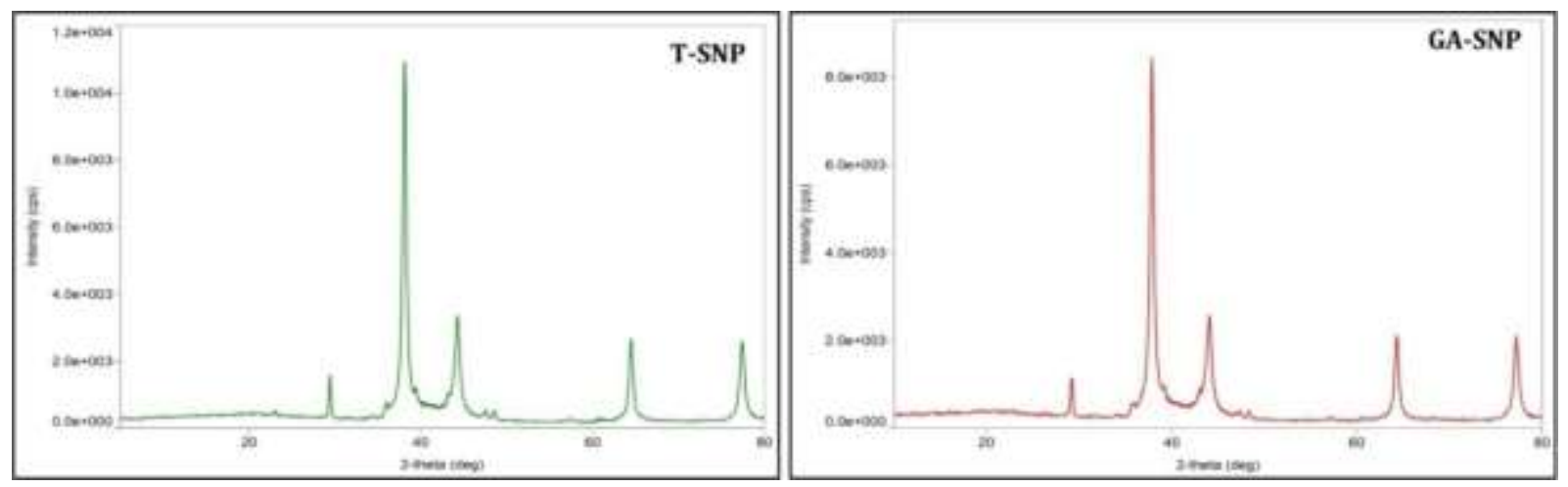

Figure 4: X-ray diffraction pattern of Thymol silver nanoparticles (T-SNPs) and Gallic acid silver nanoparticles (GASNPs) which corresponds for Bragg's reflections planes of the metallic silver nanoparticles 
Table 1: Shows the Crystallite size Dp of Gallic acid Silver nanoparticles.

\begin{tabular}{|c|c|c|c|c|}
\hline Sr. No. & Peak position $\mathbf{2 \theta} \mathbf{(}^{\mathbf{0}}$ & FWHM Bsize $\mathbf{(}^{\mathbf{0}}$ & DP (nm) & DP Average (nm) \\
\hline 1 & 22.74 & 0.26 & 32.58 & 32.38 \\
\hline 2 & 29.198 & 0.265 & 17.45 \\
\hline 3 & 35.73 & 0.50 & 19.17 \\
\hline 4 & 37.861 & 0.458 & 20.03 \\
\hline 5 & 39.14 & 0.44 & 14.45 \\
\hline 6 & 44.036 & 0.62 & 50.38 \\
\hline 7 & 47.38 & 0.18 & 30.33 \\
\hline 8 & 48.27 & 0.30 & 18.20 \\
\hline 9 & 57.32 & 0.52 & 21.84 \\
\hline 10 & 64.279 & 0.449 & 20.47 \\
\hline
\end{tabular}

Table 2: Shows the Crystallite size Dp of Thymol Silver nanoparticles

\begin{tabular}{|c|c|c|c|c|}
\hline Sr. No. & Peak position $\mathbf{2 \theta}(\mathbf{0})$ & FWHM Bsize $(\mathbf{0})$ & DP (nm) & DP Average (nm) \\
\hline 1 & 23.09 & 0.26 & 32.60 & 18.48 \\
\hline 2 & 29.402 & 0.249 & 19.43 \\
\hline 3 & 35.93 & 0.46 & 28.45 \\
\hline 4 & 38.081 & 0.452 & 14.69 \\
\hline 5 & 39.40 & 0.31 & 26.69 \\
\hline 6 & 44.231 & 0.61 & 35.03 \\
\hline 7 & 47.607 & 0.34 & 31.57 \\
\hline 8 & 48.53 & 0.26 & 21.02 \\
\hline 9 & 57.49 & 0.30 & 57.33 \\
\hline 10 & 64.442 & 0.467 & 19.52 \\
\hline
\end{tabular}

\subsection{SEM analysis of T-SNPs and GA-SNPs}

The SEM analysis of T-SNPs and GA-SNPs are presented in Fig. 5. The shape of T-SNPs is rod that ranges from $85.37 \mathrm{~nm}$ to $97.07 \mathrm{~nm}$. However, GA-SNPs are spherical in shape and size ranges from $77.75 \mathrm{~nm}$ to $125.79 \mathrm{~nm}$. Li et al. (2015) reported the GA-AgNPs were spherical in shape and nearly mono dispersed and the average size of GA-AgNPs was computed as $16.8 \pm 4.8 \mathrm{~nm}$. However, Abed et al. (2019) prepared the AgNPs using thymol and the thymol AgNPs spherical in shape.

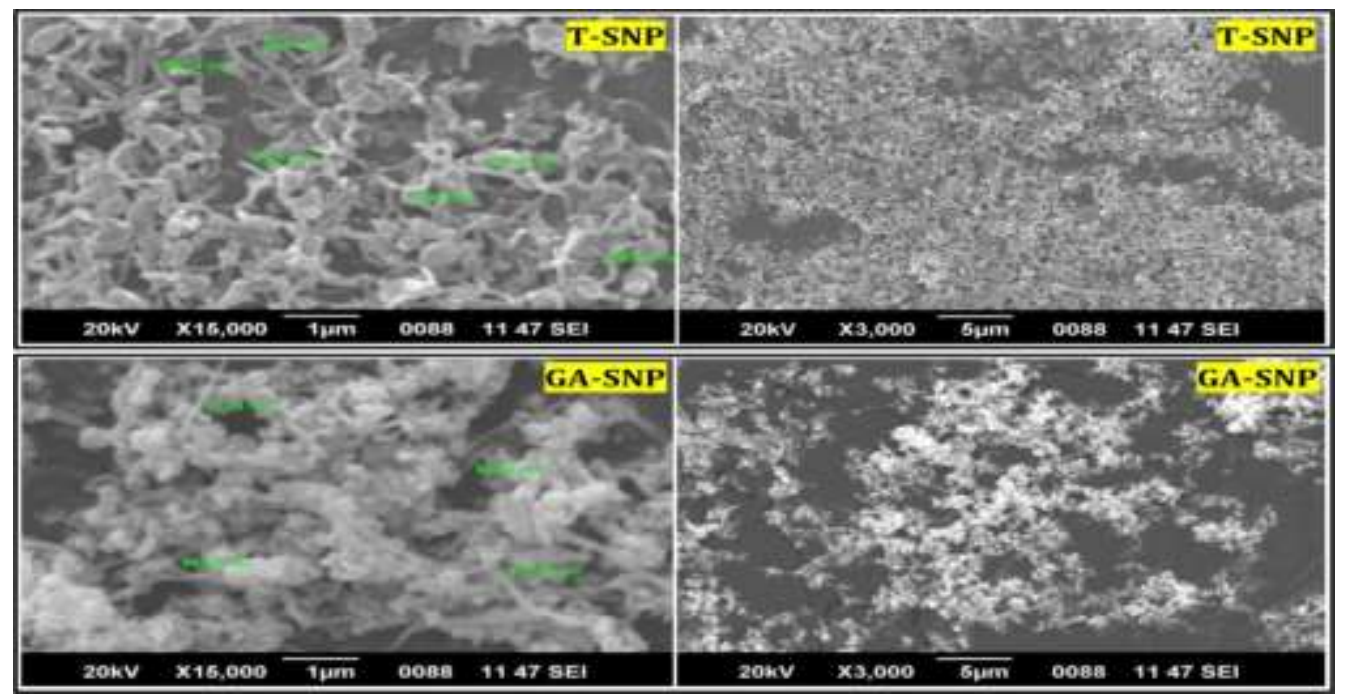

Figure 5: Shows scanning electron microscopy micrograph of Thymol silver nanoparticles (T-SNPs) and Gallic acid silver nanoparticles (GA-SNPs) 


\subsection{Antioxidant activity of Thymol, T-SNPs, Gallic acid, and GA-SNPs}

The significant antioxidant potential of Thymol, T-SNPs, Gallic acid, and GA-SNPs was evaluated by DPPH radical scavenging assay and the ascorbic acid was used as the standard drug. The IC50 values of Ascorbic acid, Thymol, TSNPs, Gallic acid, and GA-SNPs was determined to be 19.47 $\mu \mathrm{g} / \mathrm{mL}, 173.5 \mu \mathrm{g} / \mathrm{mL}, 112.1 \mu \mathrm{g} / \mathrm{mL}, 2.09 \mu \mathrm{g} / \mathrm{mL}$, and 15.19 $\mu \mathrm{g} / \mathrm{mL}$ respectively. The graphs showed percentage inhibition and DPPH free radical scavenging activity of Ascorbic acid, could be plotted and compared with Thymol, T-SNPs, Gallic acid, and GA-SNPs as shown in Table 3.

In present examination, the decrease capacity of DPPH radical was determined by the decrease in its absorbance at $517 \mathrm{~nm}$, which is induced by different antioxidants. The decrease in absorbance of DPPH radical caused by antioxidants because of the reaction between antioxidant molecules and radical progress which results in the scavenging of the radical by hydrogen donation. It can be declared that T-SNPs showed a more effective hydrogen donating capacity (IC50 - $112.1 \mu \mathrm{g} / \mathrm{mL}$ ) than pure Thymol compound. However, reverse was observed in case of Gallic acid, the pure Gallic acid showed more effective hydrogen donating capacity (IC50 - $2.09 \mu \mathrm{g} / \mathrm{mL}$ ) than GA-SNPs. Moreover, it can be concluded that pure Gallic acid more effective hydrogen donating capacity (IC50 - $2.09 \mu \mathrm{g} / \mathrm{mL}$ ) than pure standard Ascorbic acid (IC50 - $19.47 \mu \mathrm{g} / \mathrm{mL}$ ).

In the study of Bhadoriya et al. (2012) it was reported that Isolated Gallic acid showed significant in vitro free radical scavenging activity; at the concentration level of $20 \mu \mathrm{g} / \mathrm{mL}$ $1,61.45 \pm 0.44 \%$ and $52.94 \pm 0.67 \%$ inhibition of free radical was observed for ABTS and DPPH assay respectively. While $95.22 \pm 0.71 \%$ and $91.99 \pm 0.59 \%$ inhibition of free radical was observed for ABTS and DPPH assay respectively at the concentration of $50 \mu \mathrm{g} / \mathrm{mL}-1$. The Esmaeili et al. (2011) has reported the antioxidant activity of Thymol using stable radical scavenging 2, 2- Diphenyl-1-picrylhydrazyl (DPPH). The value of IC50 in this test was equal to $36.1 \pm 0.18$ which showed good effects.

\subsection{Antimicrobial activity of Thymol and Gallic acid}

The antimicrobial activity of Thymol and Gallic acid at specific concentrations were used to check the zone of inhibition values against E. coli, Klebsiella, $S$. aureus, and $S$. pasteurii. The Fig. 6 and 7 showed the antimicrobial activity of Thymol against $S$. aureus, S. pasteurii, E. coli and Klebsiella. It was observed that the Thymol showed the maximum zone of inhibition of $12 \mathrm{~mm}, 14 \mathrm{~mm}$, and $14 \mathrm{~mm}$ against the bacterium Klebsiella at the concentration of thymol 200 $\mathrm{mg} / \mathrm{ml}, 400 \mathrm{mg} / \mathrm{ml}$, and $600 \mathrm{mg} / \mathrm{ml}$. In $800 \mathrm{mg} / \mathrm{ml}$ and 1000 $\mathrm{mg} / \mathrm{ml}$ concentration of thymol showed the zone of inhibition of $16 \mathrm{~mm}$ and $17 \mathrm{~mm}$ against E. coli pathogen. Thymol shows the more antimicrobial activity than Gallic acid and when increases the concentration of Thymol and Gallic acid increased the zone of inhibition. The concentration of Gallic acid $200 \mathrm{mg} / \mathrm{ml}$ and $400 \mathrm{mg} / \mathrm{ml}$ showed the maximum zone of inhibition of $4 \mathrm{~mm}$ and $6 \mathrm{~mm}$ against the $S$. pasteurii and $600 \mathrm{mg} / \mathrm{ml}$ concentration showed $8 \mathrm{~mm}$ zone against $S$. aureus. The E. coli and $S$. aureus showed zone of inhibition of $8 \mathrm{~mm}$ and $11 \mathrm{~mm}$ at concentration $800 \mathrm{mg} / \mathrm{ml}$ and $1000 \mathrm{mg} / \mathrm{ml}$.

A report from Olasupo et al. (2003) revealed the antibacterial effect of thymol with the lowest minimum inhibitory concentration (MIC) values of $1.0 \mathrm{mmol} / \mathrm{L}(S$. typhimurium) and $1.2 \mathrm{mmol} / \mathrm{L}$ (Escherichia coli). Thymol $(200 \mathrm{mg} / \mathrm{ml})$ could inhibit the growth of $E$. coli by inducing the permeabilization and depolarization of the cytoplasmic membrane (Xu et al. 2008).

\section{11. Antimicrobial activity of T-SNPs and GA-SNPs}

The T-SNPs and GA-SNPs at specific concentrations $(60,70$, 80,90 , and $100 \mu \mathrm{l}$ ) were used to check the zone of inhibition values against E. coli, Klebsiella, S. aureus, and S. pasteurii. The zone of inhibition values for T-SNPs and GA-SNPs against E. coli, Klebsiella, S. aureus, and S. pasteurii are presented in Fig. 8 and 9. The T-SNPs showed the maximum zone of inhibition of $4 \mathrm{~mm}, 6 \mathrm{~mm}, 8 \mathrm{~mm}, 10 \mathrm{~mm}$, and $12 \mathrm{~mm}$ against the $E$. coli pathogen at the T-SNPs concentration of $60 \mu \mathrm{l}, 70 \mu \mathrm{l}, 80 \mu \mathrm{l}, 90 \mu \mathrm{l}$ and $100 \mu \mathrm{l}$. The T-SNPs all concentration showed the zone of inhibition in $E$. coli other than Klebsiella, S. aureus, and S. pasteurii pathogens.

The GA-SNPs concentration $60 \mu \mathrm{l}$ and $70 \mu \mathrm{l}$ showed the maximum zone of inhibition of $2 \mathrm{~mm}$ and $4 \mathrm{~mm}$ against $S$. aureus and E.coli. The $80 \mu \mathrm{l}, 90 \mu \mathrm{l}$ and $100 \mu \mathrm{l}$ concentration of GA-SNPs showed maximum zone of $5 \mathrm{~mm}, 6 \mathrm{~mm}$ and 8 mm against $S$. aureus pathogen. The T-SNPs show the more antimicrobial activity than GA-SNPs.

Similar to our work, $\mathrm{Li}$ et al. (2015) reported the antimicrobial activity of GA-AgNPs against two bacterial strains, Escherichia coli (E. coli) and Staphylococcus aureus (S. aureus), andone fungus, Candida albicans (C. albicans), with minimum inhibitory concentrations of 6,30 and 24 $\mu \mathrm{g} / \mathrm{mL}$ completely inhibited the growth of E. coli, $S$. aureus and $C$. albicans, respectively.

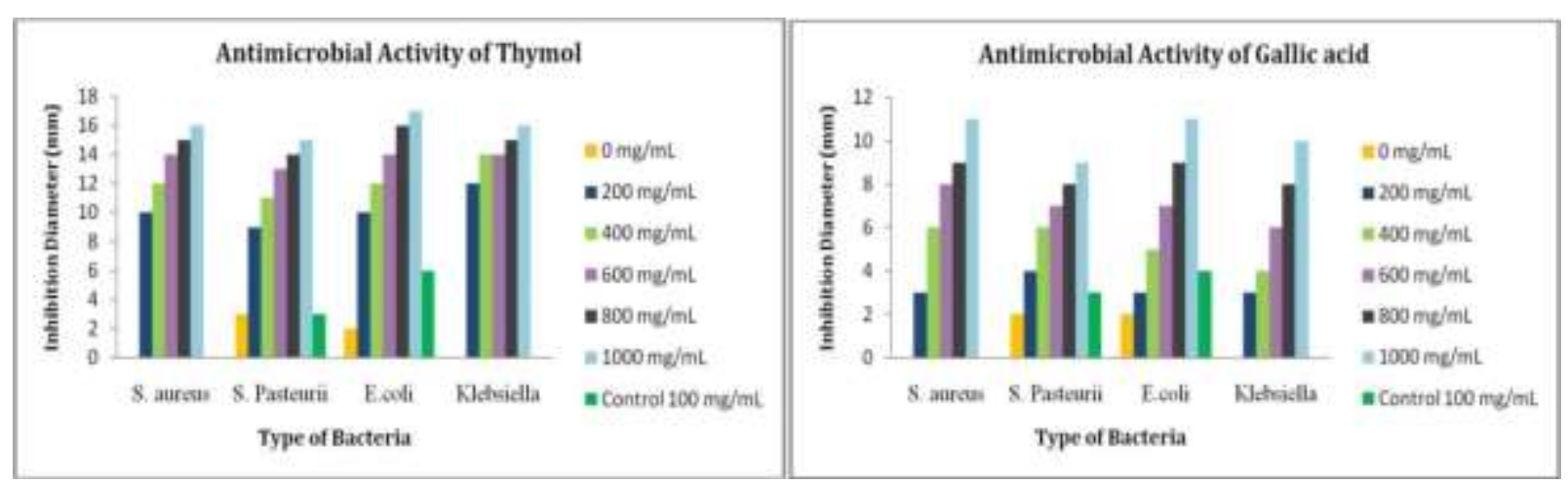

Figure 6: Graphical representation of antimicrobial activity of Thymol and Gallic acid in concentration of 0, 200, 400, 600,800 , and $1000 \mathrm{mg} / \mathrm{mL}$ against each of the four bacterial pathogens (S. aureus, S. pasteurii, E.coli, and Klebsiella) 

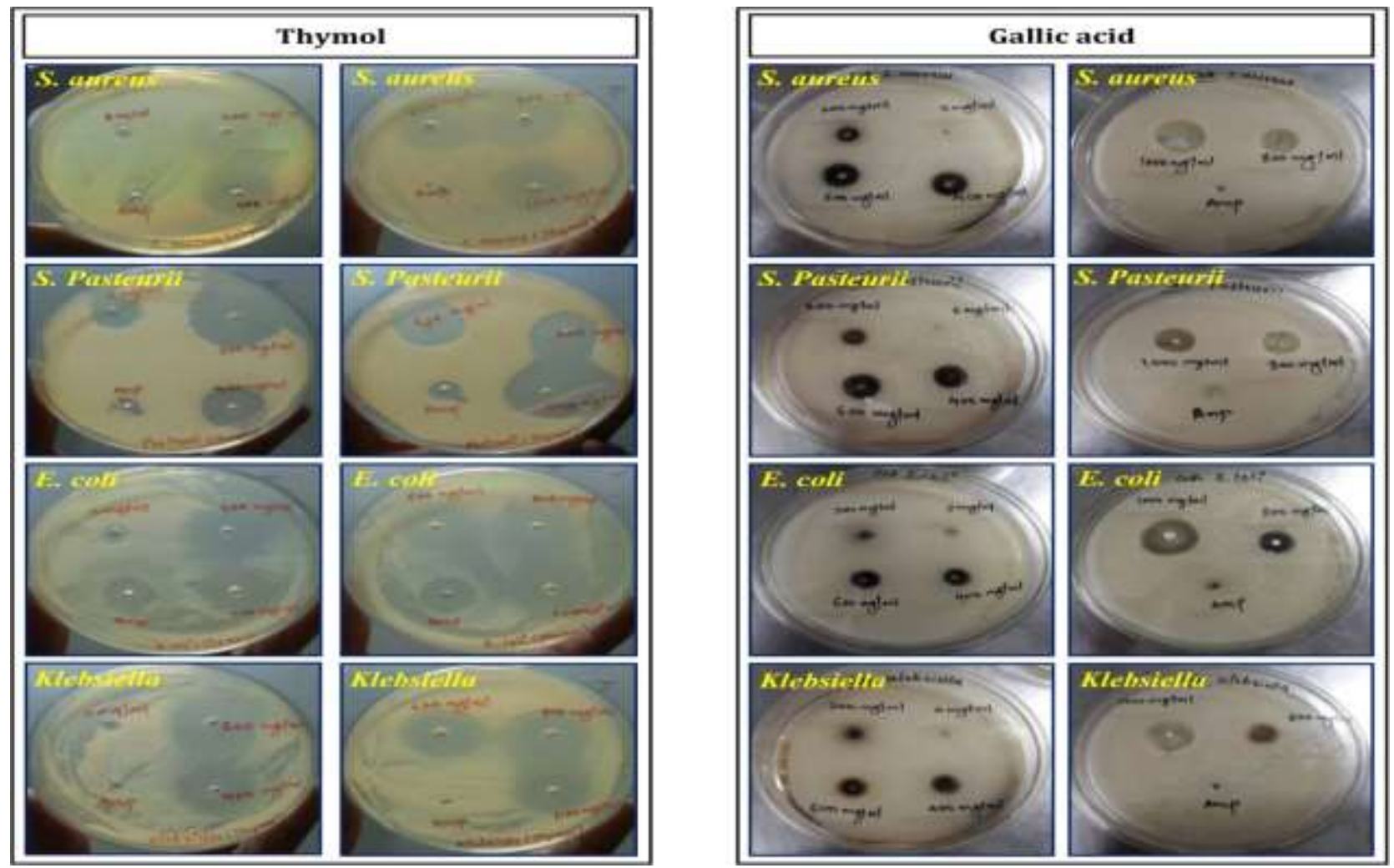

Figure 7: Agar well diffusion technique demonstrates the zone of inhibition of Thymol and Gallic acid in concentration of $0,200,400,600,800$, and $1000 \mathrm{mg} / \mathrm{mL}$ against each of the four bacterial pathogens (S. aureus, S. pasteurii, E.coli, and Klebsiella)
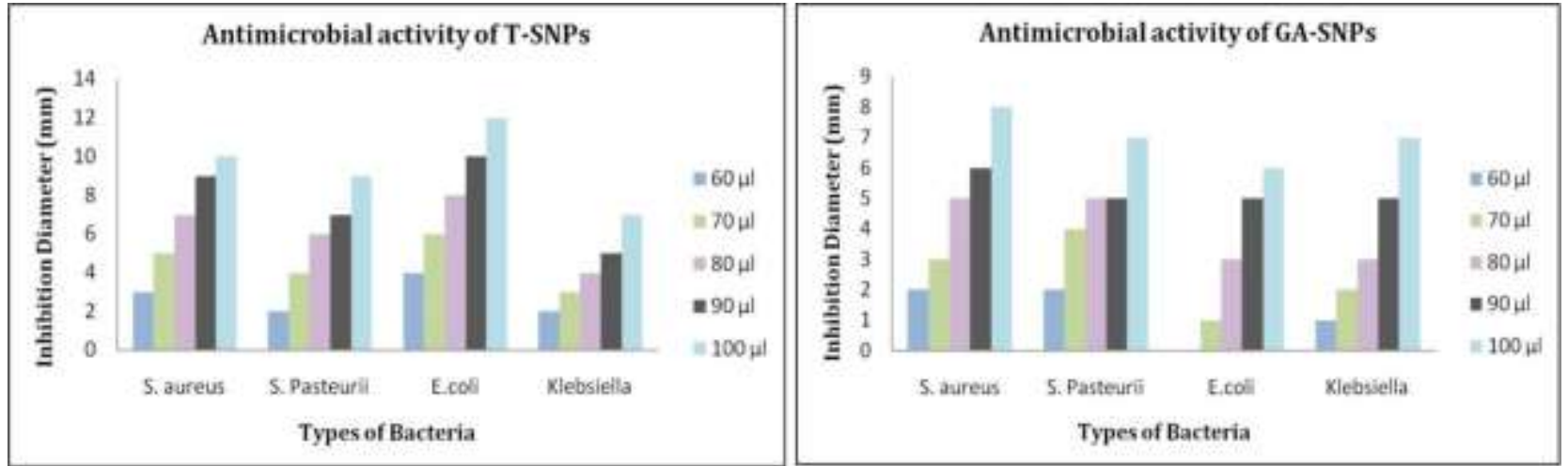

Figure 8: Graphical representation of antimicrobial activity of Thymol silver nanoparticles (T-SNPs) and Gallic acid silver nanoparticles (GA-SNPs) in concentration of 60, 70, 80, 90, and $100 \mu \mathrm{L}$ against S. aureus, S. pasteurii, E.coli, and Klebsiella
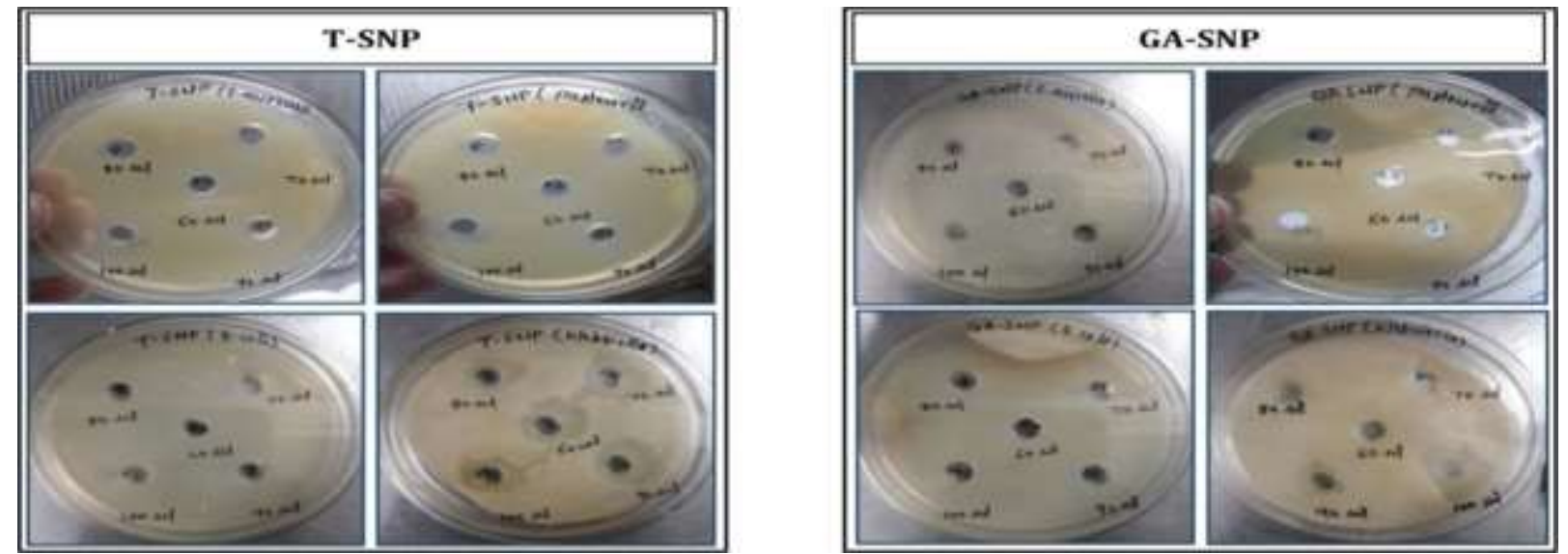

Figure 9: Agar well diffusion technique demonstrates zone of inhibition of Thymol silver nanoparticles (T-SNPs) and Gallic acid silver nanoparticles (GA-SNPs) in concentration of 60, 70, 80, 90, and 100 $\mu$ l against S. aureus, S. pasteurii, E.coli, and Klebsiella 
Table 3: DPPH radical scavenging activity of Ascorbic acid, Thymol, T-SNPs, Gallic acid, and GA-SNPs at various concentrations

\begin{tabular}{|c|c|c|c|}
\hline Sample & Concentration in $\mu \mathrm{g} / \mathrm{mL}$ & \% Inhibition & IC50 value in $\mu \mathrm{g} / \mathrm{mL}$ \\
\hline \multirow{5}{*}{ Ascorbic acid } & 5 & 25.0 & \multirow{5}{*}{19.47} \\
\hline & 10 & 27.7 & \\
\hline & 15 & 54.8 & \\
\hline & 25 & 58.7 & \\
\hline & 50 & 96.1 & \\
\hline \multirow{5}{*}{ Thymol } & 5 & 2.26 & \multirow{5}{*}{173.5} \\
\hline & 10 & 4.53 & \\
\hline & 15 & 7.31 & \\
\hline & 25 & 10.30 & \\
\hline & 50 & 15.15 & \\
\hline \multirow{5}{*}{ T-SNPs } & 5 & 13.29 & \multirow{5}{*}{112.1} \\
\hline & 10 & 15.56 & \\
\hline & 15 & 20.20 & \\
\hline & 25 & 22.37 & \\
\hline & 50 & 28.76 & \\
\hline \multirow{5}{*}{ Gallic acid } & 5 & 32.47 & \multirow{5}{*}{2.09} \\
\hline & 10 & 57.42 & \\
\hline & 15 & 82.78 & \\
\hline & 25 & 93.60 & \\
\hline & 50 & 95.87 & \\
\hline \multirow{5}{*}{ GA-SNPs } & 5 & 18.55 & \multirow{5}{*}{15.19} \\
\hline & 10 & 37.11 & \\
\hline & 15 & 59.69 & \\
\hline & 25 & 87.42 & \\
\hline & 50 & 91.95 & \\
\hline
\end{tabular}

\subsection{Visual appearance of films}

Visual appearance and colour of the film as is shown in the Fig. 10. The $\mathrm{C}+\mathrm{G}$ film was appeared as clear, glossy, smooth, and without any tents. Whereas, the visual appearance of
C+G/GA/T-SNPs film was observed as light brown colour. Kaya et al. (2018) have reports also, explained the same phenomena, that adding plant extracts to chitosan matrix and changed the film's colour.

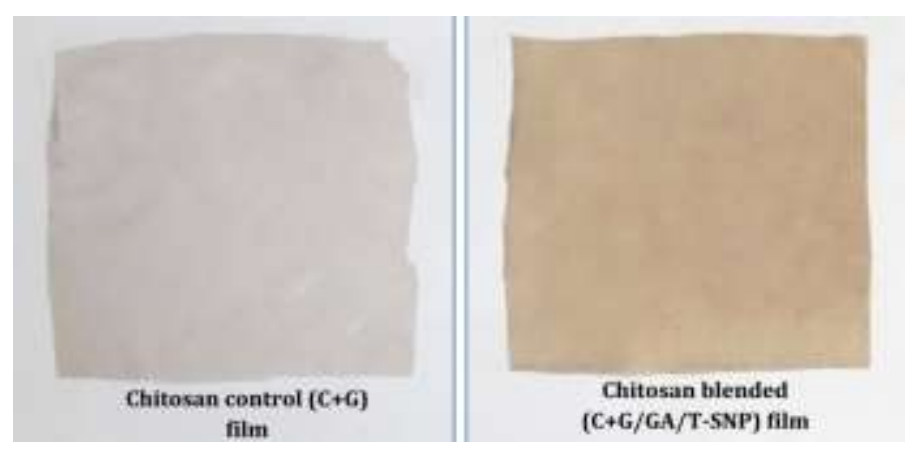

Figure 10: Visual appearance of the chitosan control $(C+G)$ film and the formulated chitosan blended $(C+G / G A / T-$ SNPs) film 


\subsection{Determination of Thickness}

Thickness of $\mathrm{C}+\mathrm{G}$ film and $\mathrm{C}+\mathrm{G} / \mathrm{GA} / \mathrm{T}-\mathrm{SNPs}$ film was measured at six different points and average thickness with standard deviation was calculated. The thicknesses of $\mathrm{C}+\mathrm{G}$ film and $\mathrm{C}+\mathrm{G} / \mathrm{GA} / \mathrm{T}-\mathrm{SNPs}$ film are $0.1 \mathrm{~mm}$ and $0.12 \mathrm{~mm}$. The data of film thickness indicates that there was slight difference in thickness within the formulations.

\subsection{Folding endurance}

Folding endurance value for $\mathrm{C}+\mathrm{G}$ film was found to be 32 folds. It indicates that $\mathrm{C}+\mathrm{G}$ film had not much satisfactory film flexibility. In contrast, $\mathrm{C}+\mathrm{G} / \mathrm{GA} / \mathrm{T}-\mathrm{SNPs}$ film was found to be more than 200 folds that indicate film had good flexibility in $\mathrm{C}+\mathrm{G} / \mathrm{GA} / \mathrm{T}-\mathrm{SNPs}$ film.

\subsection{Biodegradability of film}

Fig. 11 shows the water solubility of the $C+G$ film was recorded as $20 \%$ in $72 \mathrm{~h}$. Incorporations of Gallic acid extract and T-SNPs into the films demonstrated decrease the film solubility as $12 \%$ for $\mathrm{C}+\mathrm{G} / \mathrm{GA} / \mathrm{T}-\mathrm{SNPs}$ film. The strong intermolecular interactions between Gallic acid and T-SNPs and chitosan matrix resulted in lower degradation values into the $\mathrm{C}+\mathrm{G} / \mathrm{GA} / \mathrm{T}-\mathrm{SNPs}$ film. Lower solubility rate for the $\mathrm{C}+\mathrm{G} / \mathrm{GA} / \mathrm{T}-\mathrm{SNPs}$ film was probably due to the faster diffusion of Gallic acid and T-SNPs in water.

Fig. 12 shows that the soil degradation rates in 15 days were recorded as $100 \%$ for $\mathrm{C}+\mathrm{G}$ film and $45 \%$ for $\mathrm{C}+\mathrm{G} / \mathrm{GA} / \mathrm{T}-\mathrm{SNPs}$ film. Then after 30 days $\mathrm{C}+\mathrm{G} / \mathrm{GA} / \mathrm{T}-\mathrm{SNP}$ film was $100 \%$ Soil degradation. The $\mathrm{C}+\mathrm{G}$ film exhibited higher soil degradability; however, lower soil degradability was observed for the $\mathrm{C}+\mathrm{G} / \mathrm{GA} / \mathrm{T}$-SNPs film. Kaya et al. (2018) reported that the water solubility of the chitosan-control film was recorded as $24 \%$ in $48 \mathrm{~h}$ and Soil degradation rates in 15 days were recorded as $89.04 \%$ for chitosan control film.
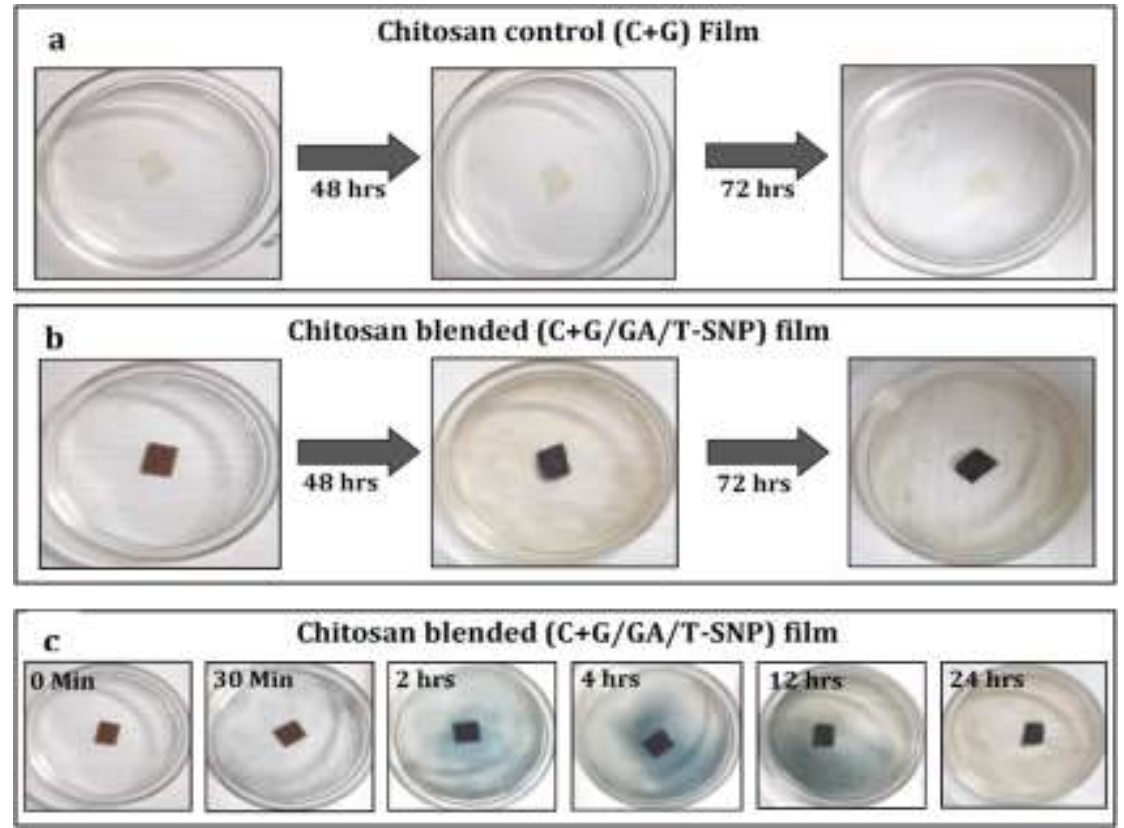

Figure 11: Biodegradability of films in water (a) chitosan control $(C+G)$ film, (b) chitosan blended (C+G/GA/T-SNPs) film, and (c) chitosan blended (C+G/GA/T-SNPs) film shows the diffusion of Gallic acid and T-SNPs in water

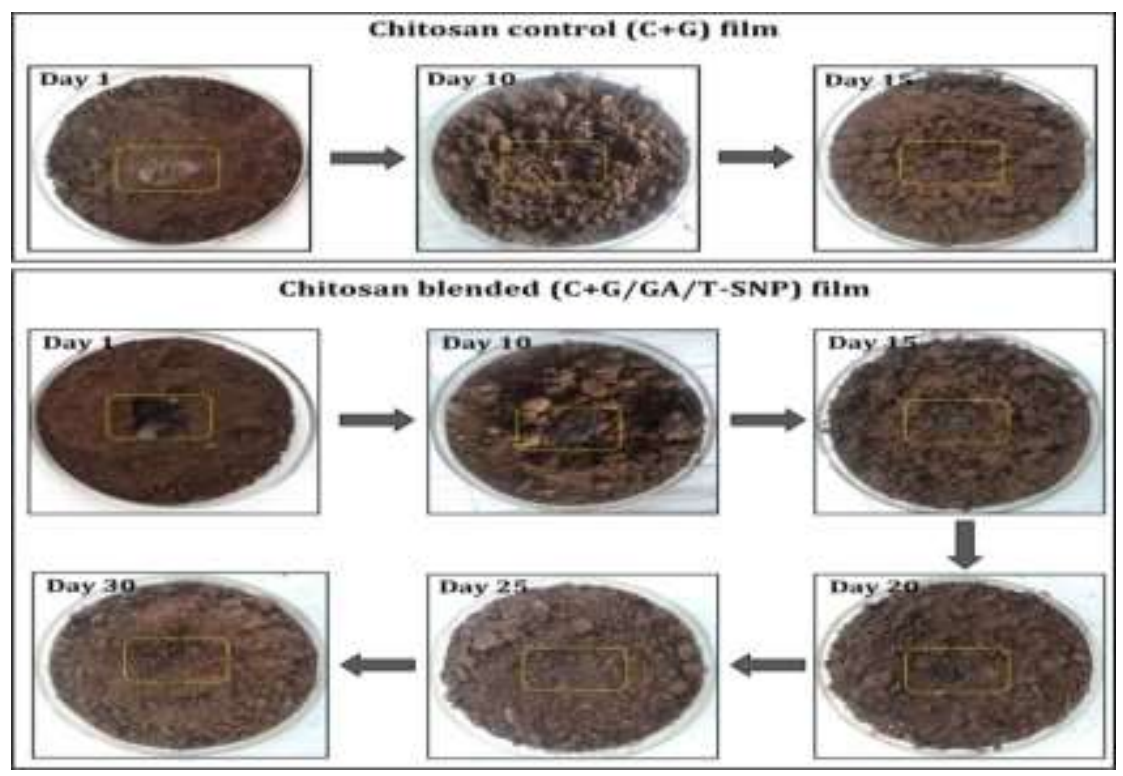

Figure 12: Biodegradability of chitosan control $(C+G)$ film and chitosan blended $(C+G / G A / T-S N P s)$ film in soil. 


\subsection{Surface $\mathrm{pH}$}

Surface $\mathrm{pH}$ of the chitosan control $(\mathrm{C}+\mathrm{G})$ film and chitosan blended ( $\mathrm{C}+\mathrm{G} / \mathrm{GA} / \mathrm{T}-\mathrm{SNPs}$ ) film were found to have $\mathrm{pH}$ between 6-7. Hence the chances of irritation are very less.

\subsection{FTIR analysis}

Fig. 13 shows the FTIR analysis of the pure chitosan, $C+G$ film and $\mathrm{C}+\mathrm{G} / \mathrm{GA} / \mathrm{T}-\mathrm{SNP}$ s film was carried out to identify the primary functional groups of the compounds. The pure chitosan FTIR spectrum is very wavy and zigzag. Also, it consists of large numbers of peaks. The FTIR spectrums of
$\mathrm{C}+\mathrm{G}$ film suggest that there is good molecular interaction between Chitosan and Glycerol. Moreover, Glycerol acts as good plasterer to chitosan as it reduces the wavy and zigzag to smooth in flow. The $\mathrm{C}+\mathrm{G} / \mathrm{GA} / \mathrm{T}-\mathrm{SNP}$ film FTIR spectrum shows that the functional group between 1800-1200 could have taken part for bending bonds, bonding bonds, modifications and interactions to form the stable film. The Fig. 13 shows the FTIR spectra of Chitosan pure, chitosan control $C+G$ film and $C+G / G A / T-S N P s$ film.

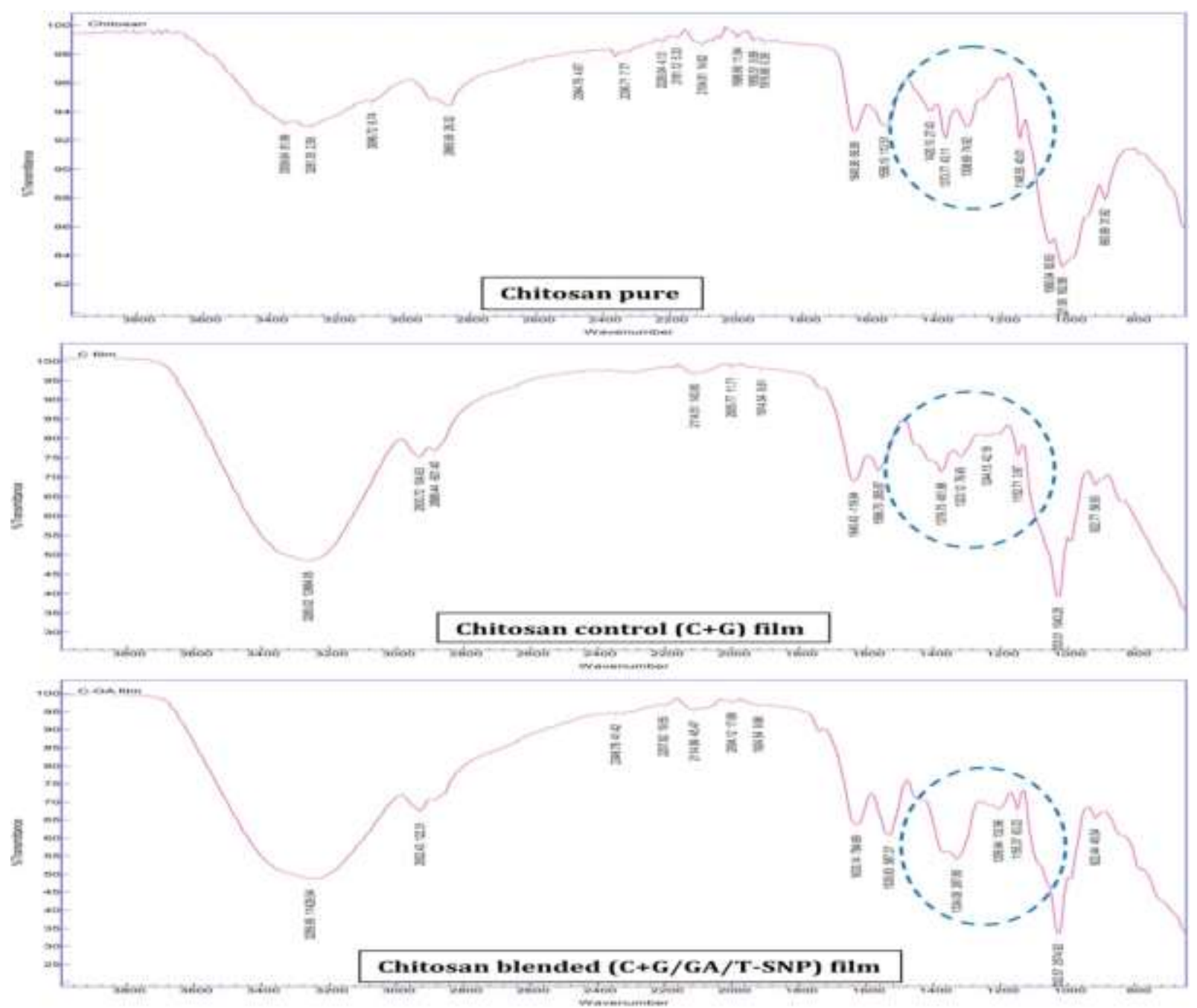

Figure 13: FTIR spectra of the pure chitosan, chitosan control $(C+G)$ film, and chitosan blended $(C+G / G A / T-S N P s)$ film was carried out to identify the primary functional groups of the compounds

It can be seen, that the FTIR of chitosan suggest the functional groups as $\mathrm{C}=\mathrm{C}$ Bending for Alkene (893.893cm-1), C-N Stretch for Amine (1021.901 cm-1, $1060.042 \mathrm{~cm}-1,1149.553 \mathrm{~cm}-1), \quad$ C-O Stretch for Aromatic ester (1308.695 cm-1), O-H bending for Phenol (1373.769 cm-1, $1420.104 \mathrm{~cm}-1), C=C$ Stretch for Alkene $(1645.897 \mathrm{~cm}-1), \mathrm{C}=\mathrm{C}=\mathrm{C}$ Stretch is Allene $(1916.665 \mathrm{~cm}-$ 1, $1950.513 \mathrm{~cm}-1,1998.658 \mathrm{~cm}-1$ ), the C $\equiv$ C Stretch at $2104.814 \mathrm{~cm}-1,2181.125 \mathrm{~cm}-1$ indicates Alkyne, $\mathrm{C} \equiv \mathrm{N}$ Stretch is Nitrile at $2226.036 \mathrm{~cm}-1$, the C-H Stretch is for Alkane (2865.094 cm-1, $3096.723 \mathrm{~cm}-1,3281.351 \mathrm{~cm}-$ 1 ), and the N-H Stretch for Aliphatic primary amine group at $3359.641 \mathrm{~cm}-1$.
It can be seen, that the FTIR $\mathrm{C}+\mathrm{G}$ film and $\mathrm{C}+\mathrm{G} / \mathrm{GA} / \mathrm{T}-$ SNPs film indicates molecular interaction between functional group as C-H Bending of Alkene $(922.770 \mathrm{~cm}$ 1), $S=0$ Stretch of Sulfoxide (1033.014 cm-1), C-N Stretch for Amine (1244.148 cm-1), $N \equiv C \equiv S$ Stretch for Isothiocyanate (2005.769 cm-1), and C-H Stretch for Alkane (2933.718 cm-1), O-H Stretch Alcohol (3265.019) between Glycerol and chitosan. The interface at the C-O Stretch which is specific for Tertiary alcohol (1152.707 cm-1) is modified to C-N Stretch known for Amine group (1155.370 cm-1). The functional group $\mathrm{S}=0$ Stretch for Sulfone $(1323.122 \mathrm{~cm}-1)$ may be displaced by C-N Stretch Aromatic amine $(1334.076 \mathrm{~cm}-$ 1). In specific, $\mathrm{O}-\mathrm{H}$ Bending which is Phenol (1379.746 $\mathrm{cm}-1$ ) is modified to $\mathrm{N}-\mathrm{O}$ Stretch Nitro compound 
(1535.832 cm-1). The peak shifting was observed in $\mathrm{C}=\mathrm{C}$ Stretch of Cyclic alkene (1566.704 cm-1) to $C=C$ Stretch (1633.135 cm-1) and $\mathrm{C}=\mathrm{C}$ Stretch Cyclic alkene $(1640.435 \mathrm{~cm}-1)$ to $\mathrm{C}=\mathrm{C}=\mathrm{C}$ Stretch allene $(1924.540 \mathrm{~cm}-$ 1). Moreover, the $\mathrm{C} \equiv \mathrm{C} \equiv \mathrm{C}$ Stretch Allene $(1914.544 \mathrm{~cm}-$ 1) is transformed to $\mathrm{N}=\mathrm{C}=\mathrm{S}$ Stretch Isothiocyanate (2004.119 cm-1). The complete transformation of $\mathrm{N} \equiv \mathrm{C} \equiv \mathrm{S}$ Stretch Isothiocyanate (2114.509) to $\mathrm{C} \equiv \mathrm{C}$ Stretch Alkyne (2207.818) and C-H Stretch Alkane (2888.438) into $\mathrm{O}=\mathrm{C}=\mathrm{O}$ Stretch Carbon dioxide (2349.779) was observed from spectrum. Kaya et al. (2018) were recorded chitosan peaks as $-\mathrm{OH}$ bonds (3288.10 cm-1), $\mathrm{C}-\mathrm{H}$ aliphatic stretching vibration (2873.78 cm-1), amide I (1651.51 cm-1), amide II (1557.79 cm-1), amide III (1374.07 cm-1) and C-O stretching vibration (1025.51 cm-1). The spectrum of chitosan film, structural changes occurred during the film formation. Addition of the glycerol to the film matrix (chitosan, acetic acid, and water), affected the intermolecular interactions resulted in expand in the $\mathrm{OH}$ bond and increase in the intensity of amide I, II, and III bands.

\subsection{X-Ray diffraction}

The crystalline structures of the $\mathrm{C}+\mathrm{G}$ film and $\mathrm{C}+\mathrm{G} / \mathrm{GA} / \mathrm{T}$ SNPs film were characterized by X-ray diffraction (XRD) see Fig. 14. Both the films have observed similar diffraction patterns, with a broad peak at $21.66^{\circ}$ and the peak is higher than 20 2-theta (deg). Indication of peak to peak in curve suggests the formation of phase or phases in the composite during polymerization process. Compressive strain to lattice structure, lattice size 20 2-theta (deg) increases. The pattern shows a complete broadening in all 2 theta values as it is nano material, the peaks are broadened. The silver nanoparticles must be embedded inside of the $\mathrm{C}+\mathrm{G}$ film. Cui et al. (2018) have reported x-ray diffraction patterns of the chitosan film has three characteristic absorption peaks at $2 \theta$ $=10.22^{0}, 19.9^{0}$, and $20.5^{\circ}$.

\subsection{SEM analysis}

The surface characterization of $\mathrm{C}+\mathrm{G}$ film and $\mathrm{C}+\mathrm{G} / \mathrm{GA} / \mathrm{T}$ SNPs film are presented in Fig. 15. As is seen from the figure, surface morphology of $\mathrm{C}+\mathrm{G}$ film was observed as small pores present in film and T-SNP are seen embedded in C+G/GA/TSNPs film which is visible and are present in surface of film. Kaya et al. (2018) reported that the chitosan-control was observed as smooth, compact, and without any crack or pores.

\subsection{Antioxidant activity}

The significant antioxidant potential of $\mathrm{C}+\mathrm{G}$ film and $\mathrm{C}+\mathrm{G} / \mathrm{GA} / \mathrm{T}-\mathrm{SNPs}$ film was evaluated by DPPH radical scavenging assay and the ascorbic acid was used as the standard drug. The IC50 values of $\mathrm{C}+\mathrm{G}$ film and $\mathrm{C}+\mathrm{G} / \mathrm{GA} / \mathrm{T}-$ SNP film were determined to be $32.85 \mu \mathrm{g} / \mathrm{mL}$ and 27.12 $\mu \mathrm{g} / \mathrm{mL}$ respectively. The graphs showed percentage inhibition and DPPH free radical scavenging activity of $\mathrm{C}+\mathrm{G}$ film and $\mathrm{C}+\mathrm{G} / \mathrm{GA} / \mathrm{T}-\mathrm{SNPs}$ film as shown in Fig. 16 (a and b) and Table 4. Kaya et al. (2018) reported that the antioxidant activities of chitosan control film were measured as $37.21 \pm 2.07 \%$.
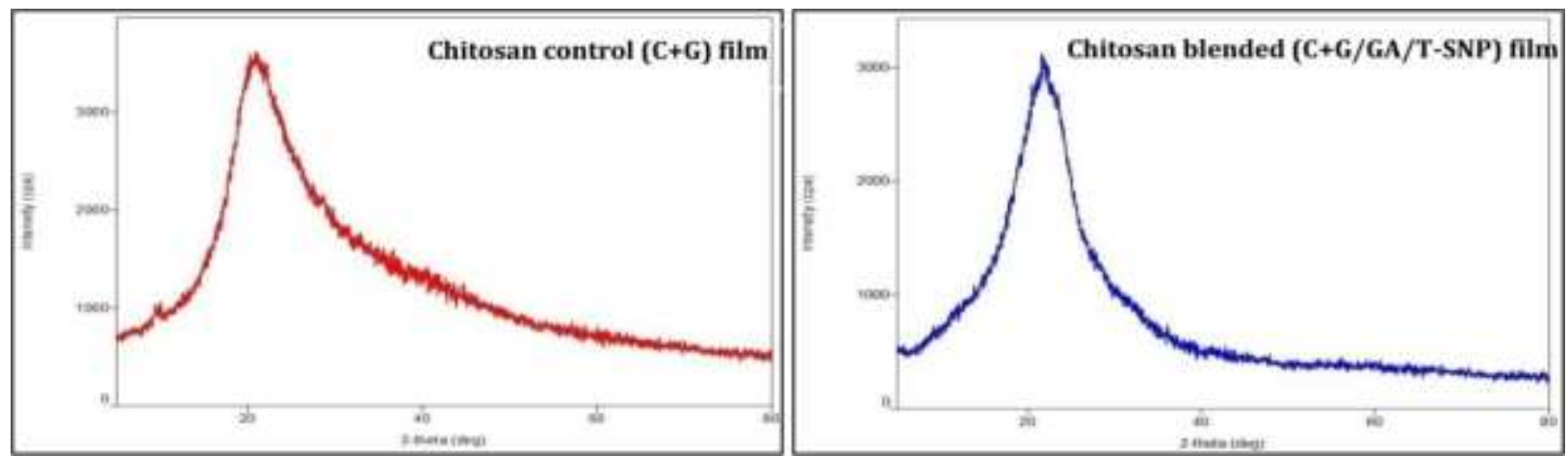

Figure 14: The $X$-ray diffraction pattern of chitosan control $(C+G)$ film and chitosan blended $(C+G / G A / T-S N P s)$ film
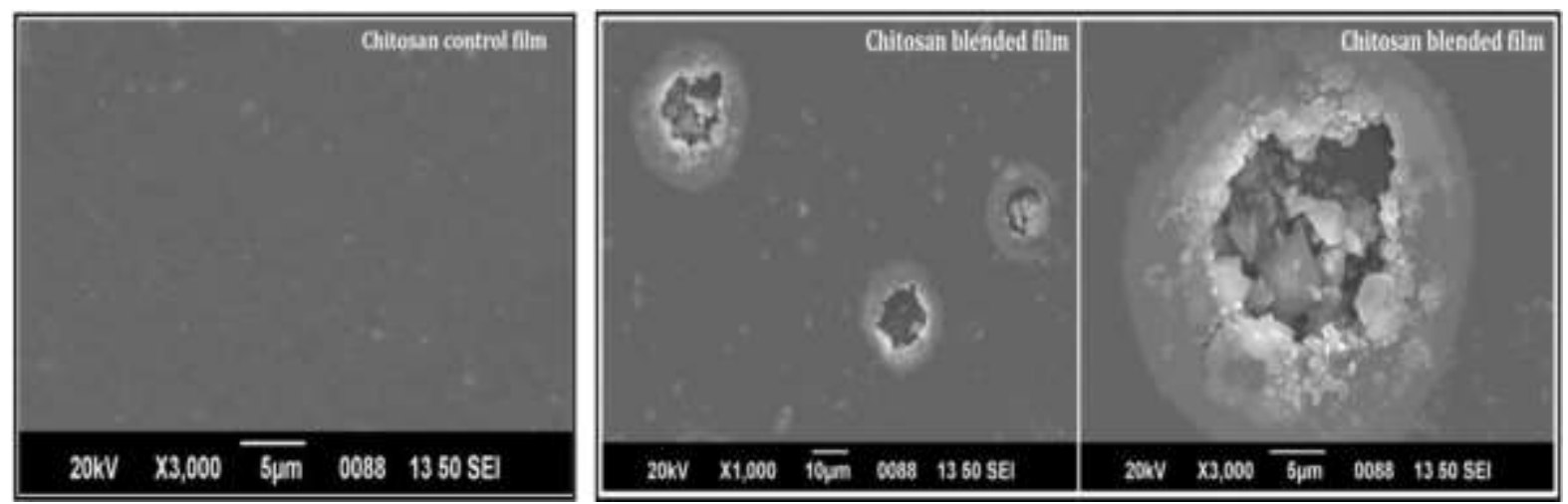

Figure 15: Shows scanning electron microscopy micrograph of chitosan control $(C+G)$ film and chitosan blended (C+G/GA/T-SNPs) film 


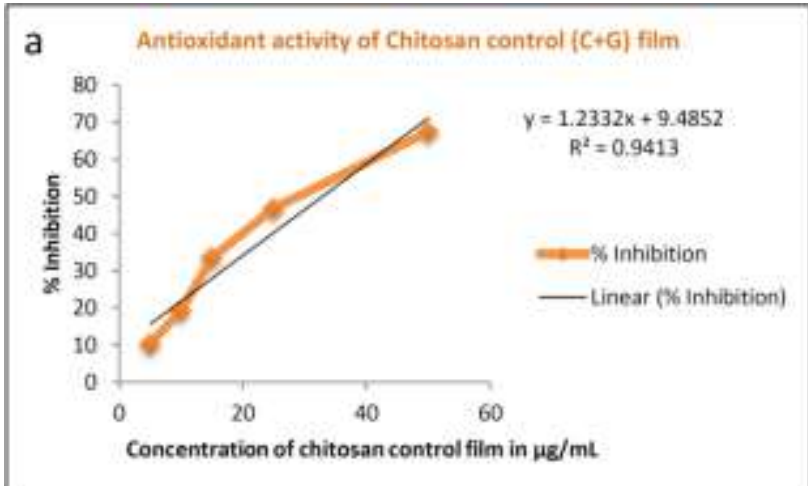

b Antioxidant activity of Chitosan blended $(\mathrm{C}+\mathrm{G} / \mathrm{GA} / \mathrm{T}-\mathrm{SNP})$ film

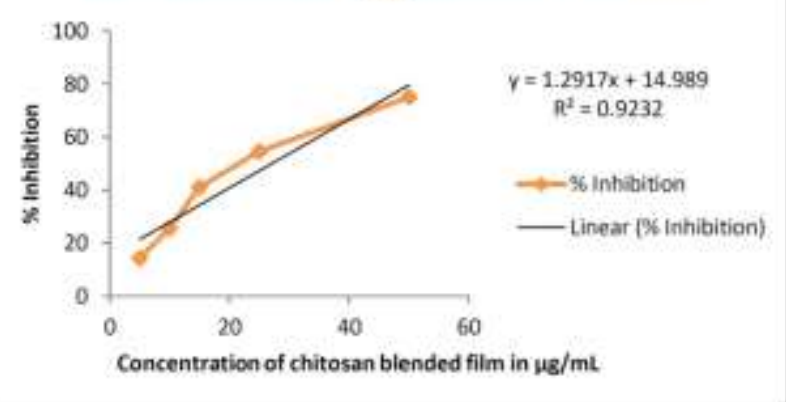

Figure 16: Shows the DPPH free radical scavenging activity of (a) chitosan control (C+G) film and (b) chitosan blended (C+G/GA/T-SNPs) film at various concentrations

Table 4: DPPH radical scavenging activity of $C+G$ film and $C+G / G A / T-S N P s$ film

\begin{tabular}{|c|c|c|c|}
\hline Sample & Concentration in $\boldsymbol{\mu g} / \mathbf{m L}$ & \% Inhibition & IC50 value in $\boldsymbol{\mu g} / \mathbf{m L}$ \\
\hline \multirow{3}{*}{ C+G film } & 5 & 10.23 & 32.85 \\
& 10 & 19.18 & \\
& 15 & 43.42 & \\
& 25 & 67.40 & \\
C+G/GA/T-SNPs film & 50 & 14.22 & 27.12 \\
& 10 & 25.56 & \\
& 15 & 41.18 & \\
\end{tabular}

\subsection{In-vitro antimicrobial activity}

The zone of inhibition values for $\mathrm{C}+\mathrm{G}$ film and $\mathrm{C}+\mathrm{G} / \mathrm{GA} / \mathrm{T}$ SNPs film against E. coli, Klebsiella, S. aureus, and S. pasteurii are presented in Fig. 17 and 18. The zone of inhibition of the $\mathrm{C}+\mathrm{G} / \mathrm{GA} / \mathrm{T}-\mathrm{SNPs}$ film is found to be very high as compared with the $\mathrm{C}+\mathrm{G}$ film. In specific, $\mathrm{C}+\mathrm{G}$ film shows ZOI of $6 \mathrm{~mm}$ for $S$. aureus, $4 \mathrm{~mm}$ for $S$. pasteurii, $5 \mathrm{~mm}$ for E. coli, and 4 $\mathrm{mm}$ for Klebsiella. However, $\mathrm{C}+\mathrm{G} / \mathrm{GA} / \mathrm{T}-\mathrm{SNPs}$ film shows the zone of inhibition of $14 \mathrm{~mm}$ for $S$. aureus, $18 \mathrm{~mm}$ for $S$. pasteurii, $13 \mathrm{~mm}$ for E. coli and $11 \mathrm{~mm}$ for Klebsiella. It is also noted that the $\mathrm{C}+\mathrm{G} / \mathrm{GA} / \mathrm{T}$-SNPs film shows more inhibition against Gram Positive Bacteria (S. aureus and S. pasteurii) than Gram Negative Bacteria (E. coli and Klebsiella). Kaya et al. (2018) reported that chitosan control film showed lower inhibition zone than blended films. The incorporating of the plant extract into chitosan films provided higher antimicrobial activity. The chitosan blend films with the plant extract were found to be effective against especially Gram-negative bacteria such as $P$. microbilis, $P$. vulgaris, $P$. Aeruginosa, and E. coli.

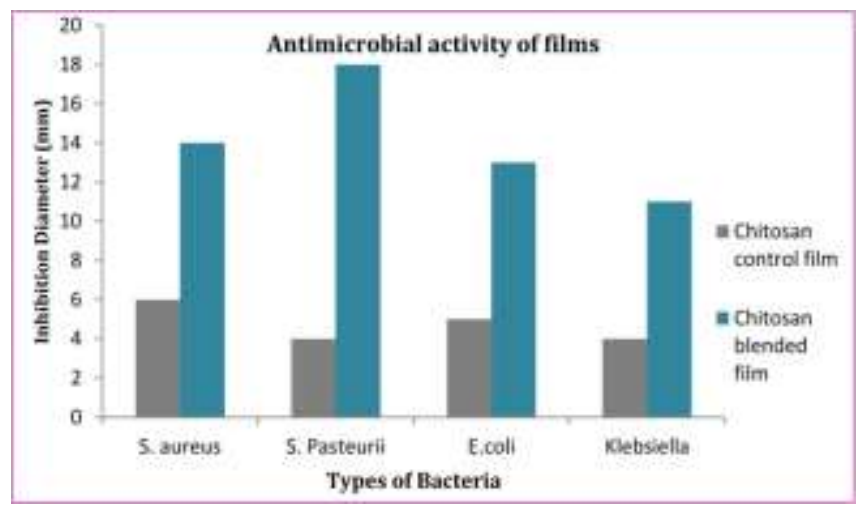

Figure 17: Graphical representation of antimicrobial activity of chitosan control $(C+G)$ film and chitosan blended $(\mathrm{C}+\mathrm{G} / \mathrm{GA} / \mathrm{T}-\mathrm{SNPs})$ film against each of the four bacterial pathogens (S. aureus, S. pasteurii, E.coli, and Klebsiella) 

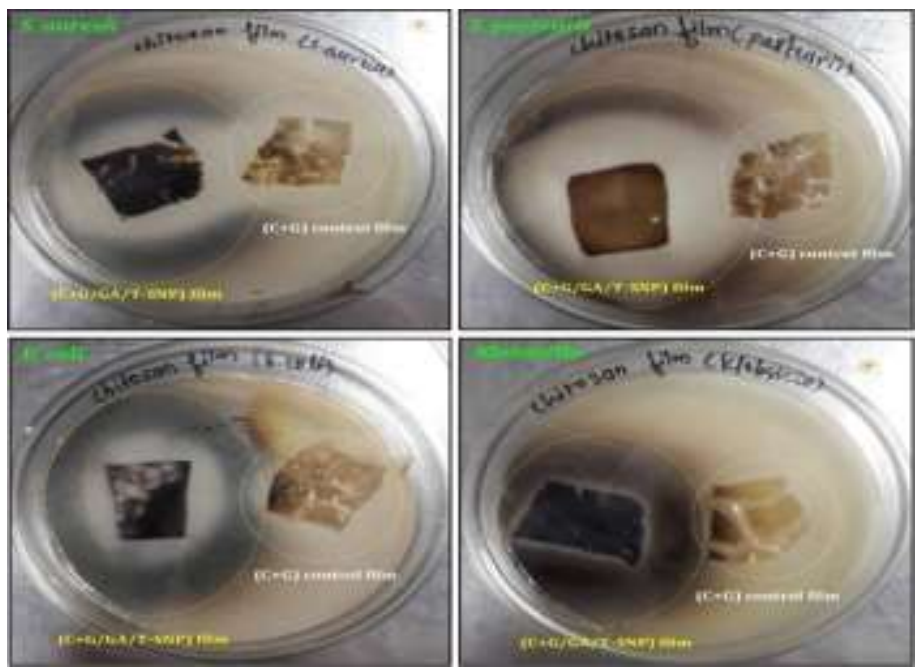

Figure 18: plate diffusion assay of chitosan control $(C+G)$ film and chitosan blended $(C+G / G A / T-S N P s)$ film against each of the four bacterial pathogens (S. aureus, S. pasteurii, E.coli, and Klebsiella)

\section{CONCLUSION}

This study explored potential aspects of Thymol, Gallic acid and T-SNPs, GA-SNPs. The T-SNPs and GA-SNPs are synthesized successfully using Thymol and Gallic acid under sunlight condition at $\mathrm{pH} 9$ and 8.5. The UV- spectroscopic analysis confirms the T-SNPs and GA-SNPs at 415 and 410 $\mathrm{nm}$. The FTIR determines the involvement of functional groups that have the potential to reduce and stabilized the T-SNPs and GA-SNPs. The surface charge of T-SNPs is -19.7 $\mathrm{mV}$ and GA-SNPs are $-20.3 \mathrm{mV}$. The IC50 values of Thymol, T-SNPs, Gallic acid, and GA-SNPs conclude that T-SNPs showed a more effective hydrogen donating capacity than pure Thymol compound. The pure Gallic acid showed more effective hydrogen donating capacity than GA-SNPs. The antimicrobial potential of Thymol and Gallic acid against E.coli, Klebsiella, S. aureus, and S. pasteurii. Thymol and Gallic acid showed high antibacterial activity against Grampositive (S. aureus and S. Pasteurii) and Gram-negative (E. coli and Klebsiella) pathogens. Higher concentration Thymol and Gallic acid resulted in an increase in the zone of inhibition. Thymol and T-SNPs showed the more antimicrobial activity than Gallic acid and GA-SNPs against $E$. coli, Klebsiella, S. aureus, and S. pasteurii pathogens, Thus TSNPs could an alternative in pharmaceutical industry for the treatment of skin infection and anesthetic for medical filed. The pure Gallic acid and T-SNPs with strong antioxidant activity may be good alternative for the developing the wound healing dressing material in pharmaceutical industry. Further, the Gallic acid (highly antioxidant) and T-SNPs (intense antimicrobial) and were transferred into $\mathrm{C}+\mathrm{G}$ films. As a result, high antioxidative and antimicrobial $\mathrm{C}+\mathrm{G} / \mathrm{GA} / \mathrm{T}-$ SNPs films (against four pathogens) were successfully produced and well characterized with commonly used analytical techniques. Additionally, the glycerol enhanced the plasticity of chitosan and the Gallic acid enhance the biodegradability time of the $\mathrm{C}+\mathrm{G} / \mathrm{GA} / \mathrm{T}-\mathrm{SNP}$ films.

\section{Acknowledgements}

The Authors would like to thank Rajiv Gandhi Biotechnology Centre, Rashtrasant Tukdoji Maharaj Nagpur University (RTMNU), Nagpur 440033, Maharashtra, India for providing lab facility. Also would like to thanks DST-SAIF Cochin, India for SEM analysis of nanoparticles. Further authors would like to thanks Department of Biotechnology, Sant Gadge Baba Amravati University for Zeta and Dynamic Light Scattering.

\section{Conflict of interest}

The authors declare that they have no conflict of interest in the publication.

\section{REFERENCES}

1. Sahinera N, Sagbasa S, Sahinerc M, Siland C, Aktase N, and Turkf M, "Agar/Chitosan IPN Thin Hydrogel Films with Antimicrobial and Antioxidant Properties for Potential Dressing Applications" Current Applied Polymer Science, 2017; 1:52-62. DOI: http://dx.doi.org/10.2174/2452271601666161209153207

2. Wang K, Pan S, Qi Z, Xia P, Xu H, Kong W, Li H, Xue P, Yang X, and $\mathrm{Fu}$, "Recent Advances in Chitosan-Based Metal Nanocomposites for Wound Healing Applications" Advances in Materials Science and Engineering, 2020; 1-13. DOI: https://doi.org/10.1155/2020/3827912

3. Kaya M, Khadem S, Cakmak YS, Mujtaba M, Ilk S, Akyuz L, Salaberria AM, Labidi J, Abdulqadira $\mathrm{AH}$ and Deligoz E, "Antioxidative and antimicrobial edible chitosan films blended with stem, leaf and seed extracts of Pistacia terebinthus for active food packaging" RSC Advances, 2017 8:3941-3950. DOI: http://dx.doi.org/10.1039/c7ra12070b

4. Fernandes FHA and Salgado HRN, "Gallic Acid: Review of the Methods of Determination and Quantification" Critical Reviews in Analytical Chemistry, 2016; 46(3):257-265. DOI: http://dx.doi.org/10.1080/10408347.2015.1095064

5. Nayeem N, Asdaq SMB, Salem H and Said AHEl-Alfqy, "Gallic Acid: A Promising Lead Molecule for Drug Development" J App Pharm, 2016; 8(2):1-4. DOI: http://dx.doi.org/10.4172/1920-4159.1000213

6. Marchese A, Orhan IE, Daglia M, Barbieri R, Lorenzo AD, Nabavi SF, Gortzi O, Izadi M and Nabavi SM, "Antibacterial and antifungal activities of thymol: a brief review of the literature" Food chemistry, 2016; 1-46. DOI: http://dx.doi.org/10.1016/j.foodchem.2016.04.111

7. Meeran MFN, Javed H, Taee HA, Azimullah S and Ojha SK, "Pharmacological Properties and Molecular Mechanisms of Thymol: Prospects for Its Therapeutic Potential and Pharmaceutical Development" Front Pharmacol, 2017; 8:134. DOI: http://dx.doi.org/10.3389/fphar.2017.00380

8. Naik S, Raikar P and Ahmed MG, "Formulation and evaluation of chitosan films containing sparfloxacin for the treatment of periodontitis" Journal of Drug Delivery \& Therapeutics, 2019; $9(1): 38-45$. http://dx.doi.org/10.22270/jddt.v9i1.2245 
9. Li D, Liu Z, Yuan Y, Liu Y and Niu F, “Green synthesis of gallic acid-coated silver nanoparticles with high antimicrobial activity and low cytotoxicity to normal cells" Process Biochemistry, 2015; 50:357-366. DOI: http://dx.doi.org/10.1016/j.procbio.2015.01.002

10. Thapliyal A and Chandra A, "Antibacterial and Anticancer Potential of Silver Nanoparticles Synthesized using Gallic Acid in Bentonite/Starch Bio-Nanocomposites" International Journal of Applied Pharmaceutics, 2018; 10(5):178-189. DOI: http://dx.doi.org/10.22159/ijap.2018v10i5.27728

11. Park J, Cha SH, Cho S and Park Y, "Green synthesis of gold and silver nanoparticles using gallic acid: catalytic activity and conversion yield toward the 4-nitrophenol reduction reaction" J Nanopart Res, 2016; 1-13. DOI: http://dx.doi.org/10.1007/s11051-016-3466-2

12. Bhadoriya U, Sharma P and Solanki SS, "In Vitro Free Radical Scavenging Activity of Gallic Acid Isolated From Caesalpinia Decapetala Wood" Asian Pacific Journal of Tropical Disease, 2012; 2:833-836. DOI: http://dx.doi.org/10.1016/S22221808(12)60274-6

13. Esmaeili A and Khodadadi A, "Antioxidant Activity of a Solution of Thymol in Ethanol" Zahedan J Res Med Sci, 2012; 14(7):14-18.

14. Lade BD, Patil AS and Paikrao HP, "Systematic optimization of thin-layer chromatography for wound-induced differential secondary metabolites in Passiflora foetida" Journal of planar chromatography, 2014; 27(5):385-391. DOI http://dx.doi.org/10.1556/JPC.27.2014.5.10

15. Lade BD and Patil AS, "Silver nano fabrication using leaf disc of Passiflora foetida Linn" Applied Nanoscience, 2017; 7(5):181-192. DOI: http://dx.doi.org/10.1007/s13204-0170558-y

16. Bhalodia NR, Nariya PB, Acharya RN and Shukla VJ, "Evaluation of in vitro Antioxidant activity of Flowers of Cassia fistula Linn" International Journal of PharmTech Research, 2011;3(1):589-599.

17. Cui L, Gao S, Song X, Huang L, Dong H, Liu J, Chen F and Yu S, "Preparation and characterization of chitosan membranes" RSC Advances, 2018; 8:28433-28439. DOI: http://dx.doi.org/10.1039/c8ra05526b

18. Tonello NV, D’Eramo F, Marioli JM, Crevillen AG and Escarpa A, "Extraction-free colorimetric determination of thymol and carvacrol isomers in essential oils by pH-dependent formation of gold nanoparticles" Microchimica Acta, 2018; 1 8. DOI: https://doi.org/10.1007/s00604-018-2893-4

19. Kumar B, Smita K, Cumbal L and Debut A, "Green synthesis of silver nanoparticles using Andean blackberry fruit extract" Saudi Journal of Biological Science, 2015; 24:45-50. DOI: http://dx.doi.org/10.1016/j.sjbs.2015.09.006

20. Lade D, Gogle D and Lade B, “Development of Silver Nanoparticles/PEG/Glycerine Composite for antibacterial effect using Leaf Extract of Ocimum sanctum and Ocimumbasilicum" Journal of Nanoscience and Technology, 2018 ; 4(5):527-532. https://doi.org/10.30799/jnst.161.18040517

21. Caputo F. Zeta Potential Determination of Nanoparticle in Aqueous Dispersion by PALS. https://sciencedocbox.com/Chemistry/86660141-

Measuring-zeta-potential.html. Accessed 11 August 2015

22. Tomaszewaska E, Katarzyna Soliwoda K, Kadziola K, TkaczSzczesna B, Celichowski G, Cichomski M, Szmaja W, and Grobelny J, "Detection Limits of DLS and UV-Vis Spectroscopy in Characterization of Polydisperse Nanoparticles Colloids" Journal of Nanomaterials, 2013; 1-10. DOI; http://dx.doi.org/10.1155/2013/313081

23. Balouiri M, Sadiki M, Ibnsouda SK, "Methods for in vitro evaluating antimicrobial activity: A review" Journal of Pharmaceutical Analysis, 2015; 6:71-79. DOI: http://dx.doi.org/10.1016/j.jpha.2015.11.005

24. Olasupo N, Fitzgerald D, Gasson M and Narbad A, "Activity of naturalantimicrobial compounds against Escherichia coli and Salmonella enteric serovar Typhimurium" Letters in Applied Microbiology, 2003; 36:448-451. DOI: http://dx.doi.org/10.1046/j.1472-765X.2003.01427.x

25. Xu J, Zhou F, Ji BP, Pei RS, and Xu N, "The antibacterial mechanism of carvacrol and thymol against Escherichia coli" Letters in Applied Microbiology, 2008; 47:174-179. DOI: http://dx.doi.org/10.1111/j.1472-765X.2008.02407.x

26. Abed MS, Abed AS and Othman FM, "Green Synthesis of Silver Nanoparticles from Natural Compounds: Glucose, Eugenol and Thymol" Journal of Advanced Research in Fluid Mechanics and Thermal Sciences, 2019; 60(1):95-111. 